\title{
Bearing Characteristics of Composite Pile Group Foundations with Long and Short Piles under Lateral Loading in Loess Areas
}

\author{
Tianzhong Ma $\mathbb{D}^{1,2}$ Yanpeng Zhu, ${ }^{1,2}$ Xiaohui Yang $\mathbb{D},{ }^{1,2}$ and Yongqiang Ling ${ }^{1,2}$ \\ ${ }^{1}$ Key Laboratory of Disaster Prevention and Mitigation in Civil Engineering of Gansu Province, Lanzhou University of Technology, \\ Lanzhou 730050, China \\ ${ }^{2}$ Western Engineering Research Center of Disaster Mitigation in Civil Engineering of Ministry of Education, \\ Lanzhou University of Technology, Lanzhou 730050, China
}

Correspondence should be addressed to Xiaohui Yang; yxhui86@126.com

Received 24 April 2018; Revised 27 August 2018; Accepted 6 September 2018; Published 12 November 2018

Academic Editor: Evangelos J. Sapountzakis

Copyright (C) 2018 Tianzhong Ma et al. This is an open access article distributed under the Creative Commons Attribution License, which permits unrestricted use, distribution, and reproduction in any medium, provided the original work is properly cited.

It is very necessary to research the bearing characteristics of composite pile group foundations with long and short piles under lateral load in loess areas, because these foundations are used widely. But few people researched this problem in loess areas up to now worldwide. In this paper, firstly, an indoor test model of a composite pile foundation with long and short piles is designed and then employed to explore the vertical load bearing characteristics and load transfer mechanisms of a single pile, a four-pile group, and a nine-pile group under different lateral loads. Secondly, ANSYS software is employed to analyze the load-bearing characteristics of the test model, and for comparison with the experimental results. The results demonstrate the following. (1) The lateral force versus pile head displacement curves of the pile foundation exhibit an obvious steep drop in section, which is a typical feature of piercing damage. A horizontal displacement limit of the pile foundation is $10 \mathrm{~mm}$ and $6 \mathrm{~mm}$ for the ones sensitive to horizontal displacement. (2) The axial force along a pile and frictional resistance do not coincide, due to significant variations and discontinuities in the collapsibility of loess; a pile body exhibits multiple neutral points. Therefore, composite pile groups including both long and short piles could potentially maximize the bearing capacity and reduce pile settlement. (3) The distribution of stress and strain along the pile length is mainly concentrated from the pile head to a depth of about $1 / 3$ of the pile length. If the lateral load is too large, short piles undergo rotation about their longitudinal axis and long piles undergo flexural deformation. Therefore, the lateral bearing capacity mainly relies on the strength of the soil at the interface with the pile or the horizontal displacement of the pile head.

\section{Introduction}

Pile foundation is one of the most common deep foundation forms employed for supporting superstructures in collapsible loess regions. Significant achievements have been made in the selection of pile foundations $[1,2]$, characterization of load bearing capacity $[3,4]$, and investigation of negative frictional resistance $[5,6]$. However, geotechnical engineering activities conducted in loess regions often encounter multiple stiff bearing layers, which is similar to conditions encountered in coastal areas. Such discontinuities in the characteristics of collapsible loess add considerably greater complexity to the optimal design of pile foundations [7]. In response to these conditions, the lower limit value of depth collapsibility is a bit conservative [8-10], so composite pile foundations with long and short piles have gained increasing interest.

Research regarding composite pile foundation with long and short piles has typically focused on single pile deformation characteristics under vertical loading and has employed numerous research methods including theoretical analysis, field or laboratory test, and numerical simulation. However, the extent of research focused on pile groups is considerably less. S.C.Wong et al. [11] investigated the interaction of different pile lengths and suggested that the pile interaction coefficient exhibits obvious differences under these conditions. Y. F.Leung et al. [12] proposed an analysis method based on elastic theory that focused on optimizing the pile lengths 
of pile raft foundations to improve the overall stiffness. However, the calculation becomes very complex with an increasing number of piles. Z.J.Wang et al. [13] deduced an analytical expression for the settlement of a single pile in a homogeneous soil layer and applied it to stratified soils. J.H.Xiong et al. [14] experimentally investigated model composite pile foundations with long and short piles composed of four-pile and nine-pile groups and evaluated the load bearing properties for different pile lengths. M.S.Huang et al. [15] employed centrifugal model testing and a three-dimensional (3D) finite element method to investigate the load sharing behavior of composite pile foundation groups composed of different pile lengths under embankment loading. X.N.Ma et al. [16] conducted field testing and numerical simulations and provided a detailed analysis of the characteristic lengths of settlement for composite pile foundations. D.A.Brown et al. [17] conducted a series of 3D FEM studies on the behavior of single pile and pile group with elastic-plastic soil model. X.S.Ge et al. [18] investigated that composite pile foundations with long and short piles can ensure a more uniformly distributed foundation stress and thereby reduce the extent of foundation settlement. M.Achmus et al. [19] and H.H.Zhang et al. [20] investigated composite pile foundations under vertical and horizontal loading, evaluated the complex interaction between piles and soil, and proposed a method about common function analysis. L.Zhang et al. [21] investigated bearing capacity of single pile under horizontal load in layered soils. It was determined that the foundations of high-rise buildings under horizontal loading (e.g., loading from wind, earthquakes, and soil lateral pressure) are subject to increased horizontal shear forces and overturning moments. As such, high-rise building foundations must not only bear vertical loads, but also resist horizontal loading. Therefore, the load bearing properties of composite pile foundations with long and short piles must be more fully investigated under simultaneous vertical and horizontal loading.

This paper presents the design of an indoor composite pile foundation test model with long and short piles. The model was employed to explore the vertical load bearing characteristics and load transfer mechanism of pile groups composed of a single pile, four piles, and nine piles under different lateral loads. The ANSYS finite element software was employed to analyze the load-bearing characteristics of the test model, and comparisons verify the feasibility of applying composite pile foundations with long and short piles in loess areas. The findings of this study can provide guidance for pile foundation optimization in loess areas.

\section{Test Program}

2.1. Model Enclosure and Test Piles. Experimental testing employed the cubic model enclosure illustrated in Figures 1 and 2. The enclosure was $1.1 \mathrm{~m}$ on each side. Angle iron was welded along each side of the cube, and the bottom plane was $1 \mathrm{~cm}$ thick steel plate in which eight drainage ports were drilled. $1 \mathrm{~cm}$ thick organic glass was placed all around; organic glass and angle iron were connected by bolt.
TABLE 1: Physical parameters of loess.

\begin{tabular}{lcccc}
\hline$d_{\mathrm{s}}$ & $w_{\mathrm{p}}(\%)$ & $w_{\mathrm{L}}(\%)$ & $\rho_{d \max }\left(\mathrm{g} / \mathrm{cm}^{3}\right)$ & $w(\%)$ \\
\hline 2.71 & 16.3 & 29.5 & 1.76 & 12.7 \\
\hline
\end{tabular}

Attached to the bottoms of the test piles were springs with varied stiffness coefficients to simulate soil layers of different load bearing characteristics. Collapsible loess obtained from Longxi county of China was employed as fill material in the model enclosure, and its basic physical and mechanical parameters are listed in Table 1 . The foundation soil was added in $80 \mathrm{~mm}$ layers. The volume density and water content of the foundation soil were consistent with natural loess. All tested piles were $70 \mathrm{~mm}$ in diameter and were composed of C30 concrete. The length of long pile was $1,100 \mathrm{~mm}$, and the length of short pile was $850 \mathrm{~mm}$.

2.2. Strain Components of Pile Bodies. Strain testing of the model piles was conducted using foil type resistance strain gauges. A pair of resistance strain gauges was symmetrically placed evenly along the length of the piles, beginning with the bottom, to ensure the accuracy of the measurement results. As illustrated in Figure 3, strain gauges were placed at $8 \mathrm{~cm}$, $23 \mathrm{~cm}, 38 \mathrm{~cm}, 53 \mathrm{~cm}$, and $68 \mathrm{~cm}$ from the bottom of the short pile body, including a total of five strain gauge pairs, and strain gauges were placed at $9 \mathrm{~cm}, 23 \mathrm{~cm}, 37 \mathrm{~cm}, 51 \mathrm{~cm}, 65 \mathrm{~cm}$, $79 \mathrm{~cm}$, and $93 \mathrm{~cm}$ from the bottom of the long pile body, for a total of 7 strain gauge pairs. The strain gauges were protected from moisture contamination by coating the gauges using silica gel. Strain gauge was connected by a quarter bridge. Static strain gauge data was collected using a high speed data acquisition system.

2.3. Test Loading. Testing was conducted using a pseudostatic loading test system. A 30 t load sensor was positioned on the top surface of each pile to measure the vertical load, and a $2 \mathrm{~cm}$ thick steel plate was placed over the load sensors on the top surfaces of the piles. In order to make level, cushion sandbags were placed between the load sensor and pile head. Vertical settlement and horizontal displacement of the pile top were measured by displacement sensors. A hydraulic jack with a digital display was employed for applying the vertical load. To guarantee the stability of the vertical load, testing was suspended momentarily to ensure an accurate loading due to the settlement of the pile foundation.

Horizontal load testing was conducted for a single pile, four piles, and nine piles using the apparatus shown in Figure 4. Vertical load testing indicated that the vertical ultimate bearing capacities of the single pile \#2 (short), single pile \#7 (long), four-pile group (\#4 [long], \#5 [short], \#9 [long], and $\# 10$ [short]), and nine-pile group (\#1-\#3\# [long except for \#2], \#6-\#8 [short except for \#7], and \#11-\#13 [long, short, long, respectively]) are $3.39,4.34,16$, and $32 \mathrm{kN}$, respectively. During horizontal load testing, a vertical load of 0.8 times the ultimate vertical bearing capacity of a pile was firstly applied, and then horizontal loading was conducted at a strain rate of $0.02 \mathrm{~mm} / \mathrm{s}$. It should be noted that, due to the level of 


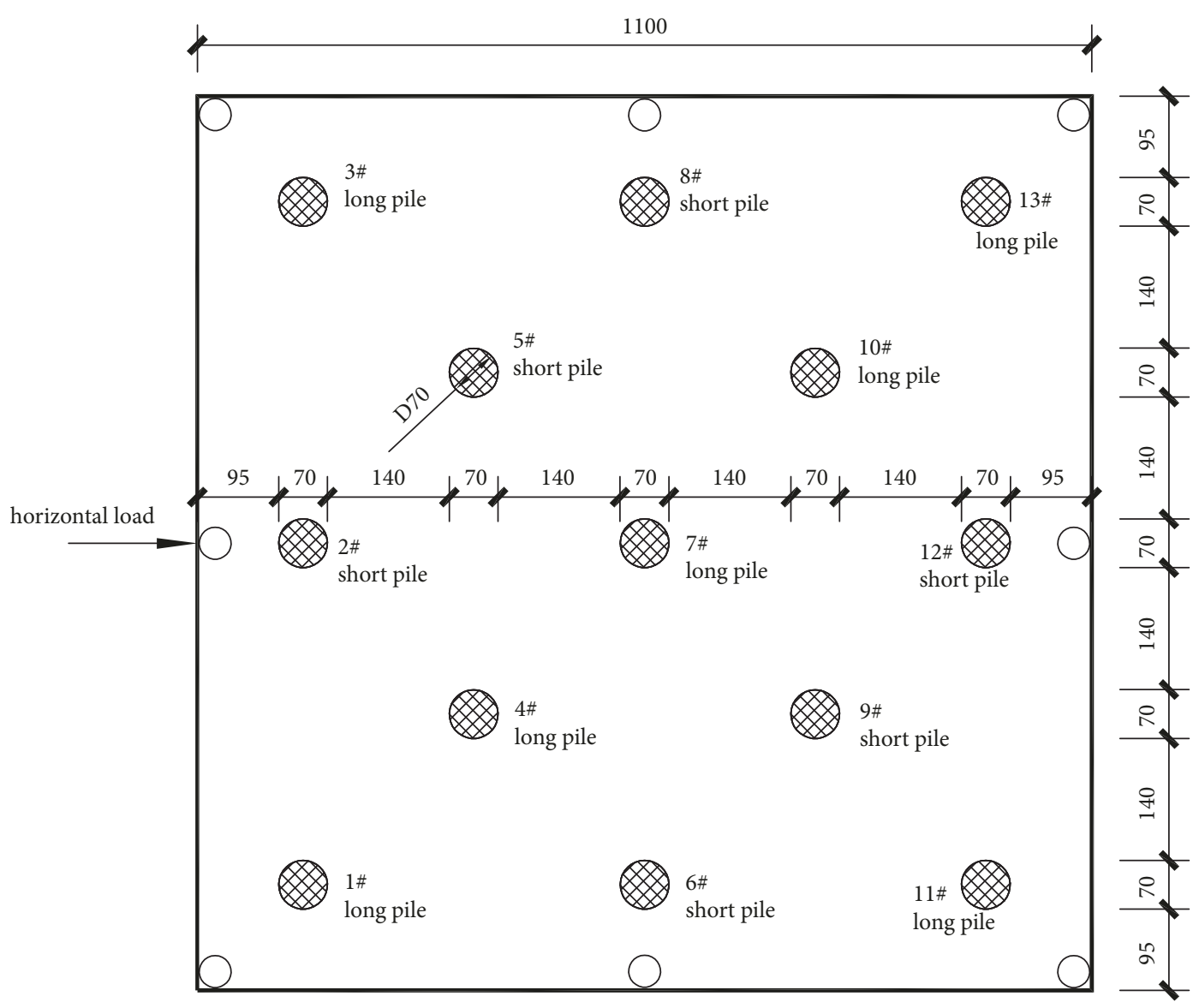

FIGURE 1: Plane arrangement of the test model.

single pile loading test, nine-pile load \#2 and \#7 piles and pile top force steel failed to connect, practical for seven-pile load. Because the horizontal load testing conducted was relatively limited, the horizontal displacement of a pile head was limited to a maximum of $2 \mathrm{~cm}$.

\section{Analysis of Test Results}

3.1. Displacement of the Pile Head with respect to Horizontal Load. Applied at the top of the pile under 0.8 times vertical ultimate bearing capacity, single pile (\#2 and \#7 piles), fourpile (\#4, \#5, \#9, \#10 piles), and seven-pile (\#1, \#3, \#6, \#8, \#11 $\# 13$ piles) side sway displacement $S$ of pile top change with horizontal thrust $\mathrm{F}$ curve is shown in Figure 5.

The displacements $S$ of the pile head/s with respect to the applied horizontal load to the single pile, four-pile group, and seven-pile group are shown in Figure 5. We note that the F-S curves essentially present a linear relationship when the horizontal load is small. However, with increasing load, the curves gradually become nonlinear. The short piles in particular exhibit an obvious turning point at a given load, which is a typical feature of piercing damage. The turning point for the single \#2 pile (short pile) occurs at a force of $2.8 \mathrm{kN}$, with a corresponding displacement of $3.97 \mathrm{~mm}$. The turning point for the single \#7 pile (long pile) occurs at a force of $3.5 \mathrm{kN}$, with a corresponding displacement of $4.95 \mathrm{~mm}$, which is greater than that of the \#2 pile. The turning point of the four-pile group occurs at a force of about $6 \mathrm{kN}$, with displacements of $3-4.5 \mathrm{~mm}$. The turning point of the seven-pile group occurs at a force of about $13 \mathrm{kN}$, with displacements of 5-7.1 mm.

We observed that the short piles within a pile group are damaged with increasing horizontal loading prior to the long piles, and the short piles may be under a normal load when they are damaged. Displacement is an important factor affecting the bearing capacity of pile foundations; however, testing was discontinued after the head of the short piles exceeded the $2 \mathrm{~cm}$ displacement limit, even though the long piles or the overall pile structure had suffered no damage. For loess areas that lack static load test of pile group level, in conjunction with the current "technology code for building pile foundations" (JGJ 94-2008), a horizontal displacement limit of $10 \mathrm{~mm}$ is recommended; that for horizontal displacement sensors is $6 \mathrm{~mm}$. Therefore, big thickness of loess foundation and bearing capacity of pile foundation design are not only the design standards and should be combined with regional experiences. Pile foundation design shall provide an adequate pile length-diameter ratio according to the requirements of the upper structure and the tensile strength of piles with consideration for permissible pile displacement values. To 


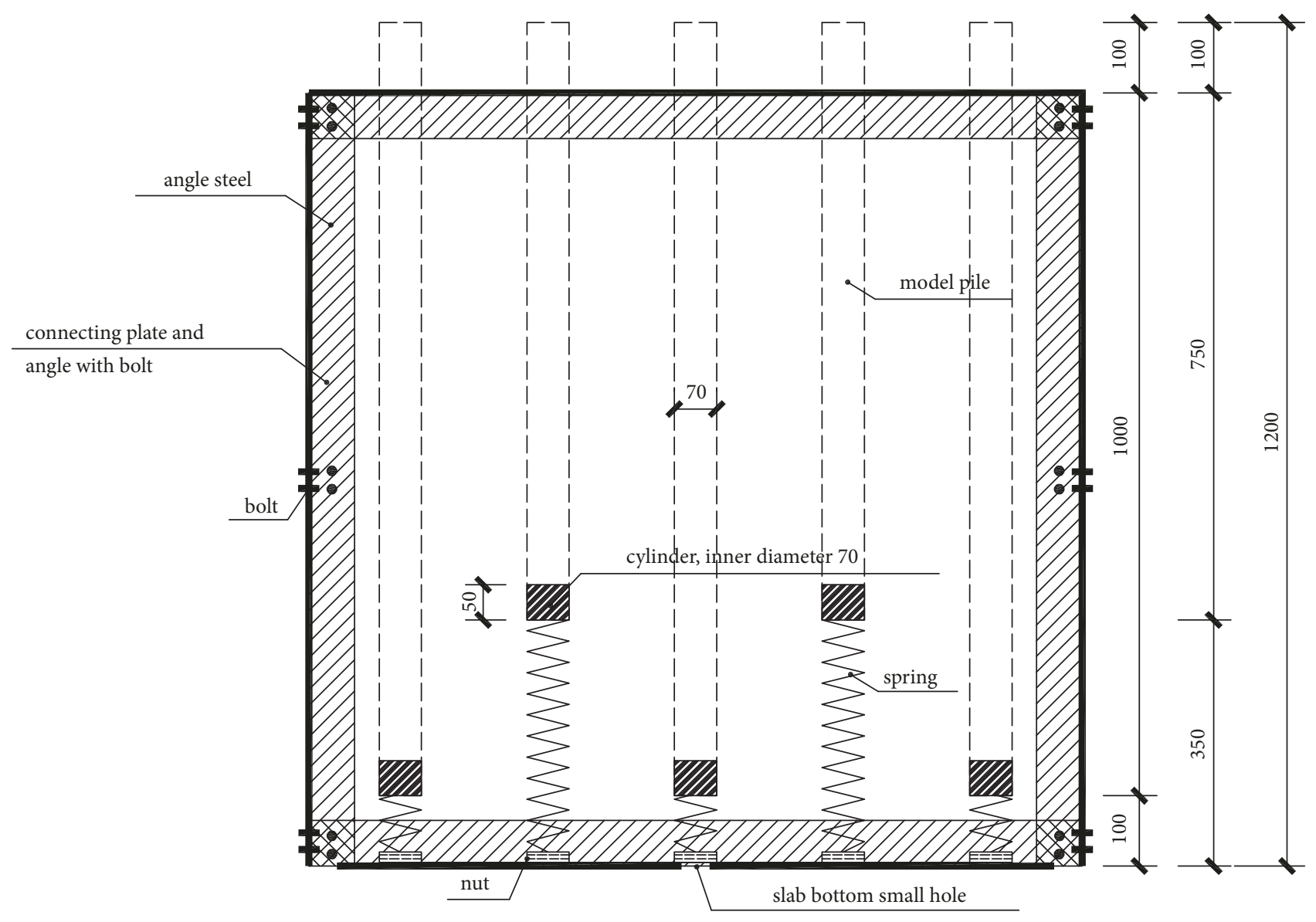

FIGURE 2: Elevation arrangement of the test model.

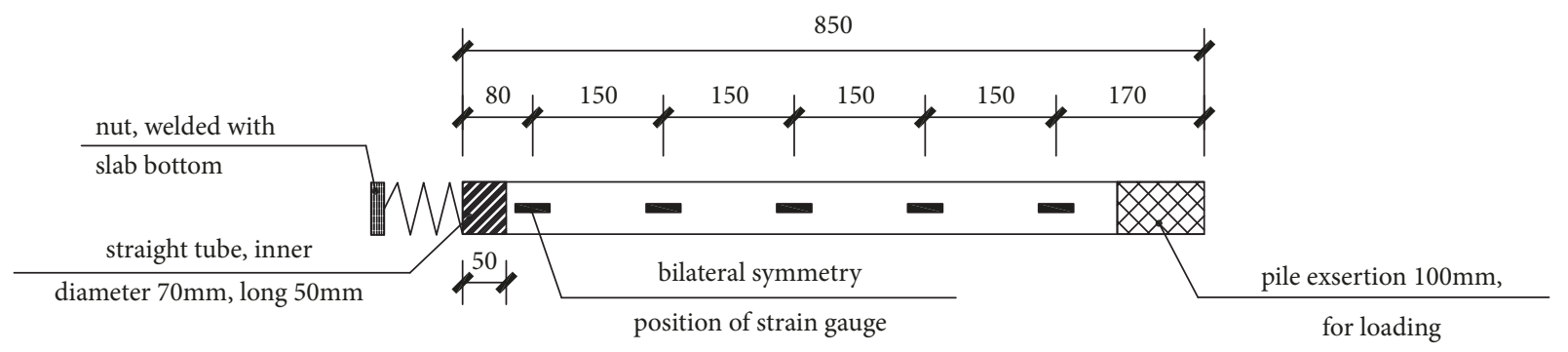

(a) Short pile

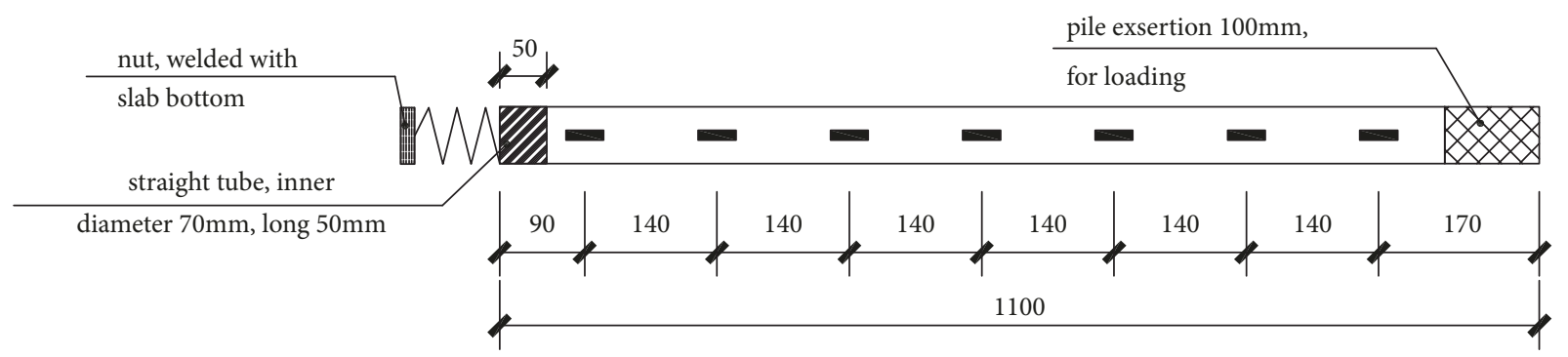

(b) Long pile

FIGURE 3: Arrangement of strain gauges on the short and long piles. 


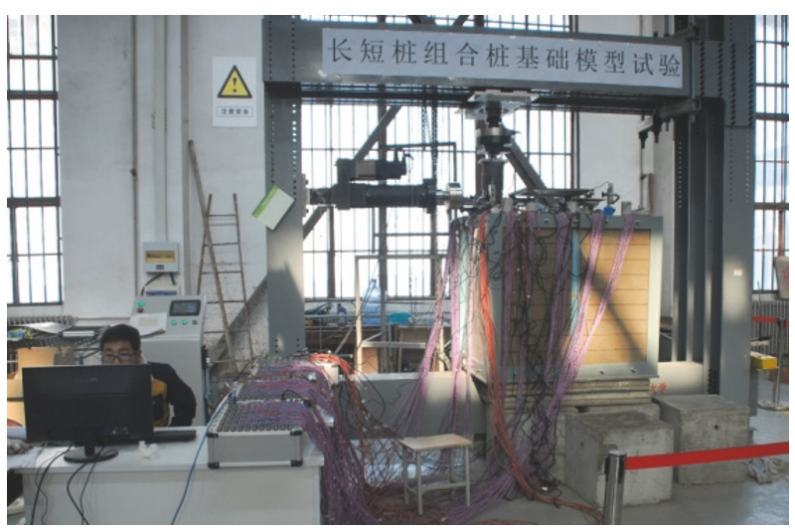

FIGURE 4: Image of testing facility.

$F(\mathrm{kN})$

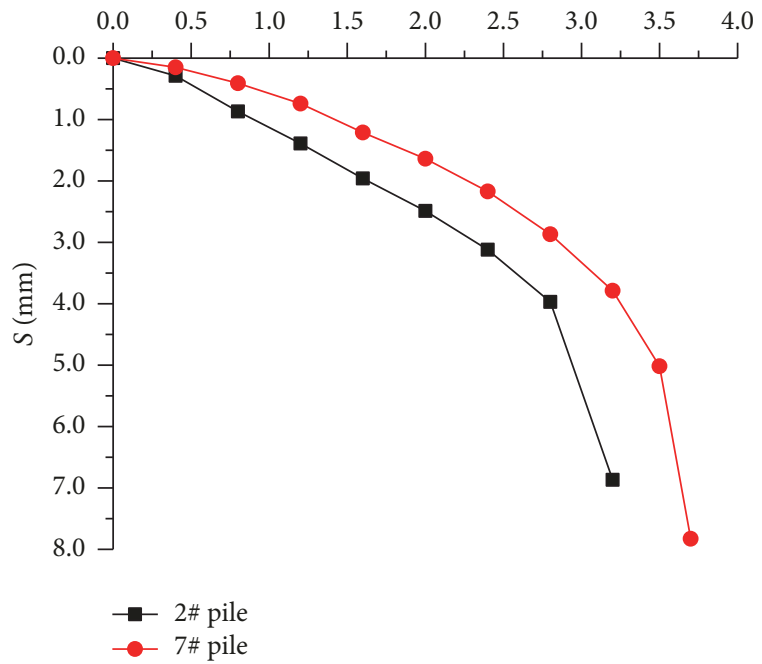

$F(\mathrm{kN})$

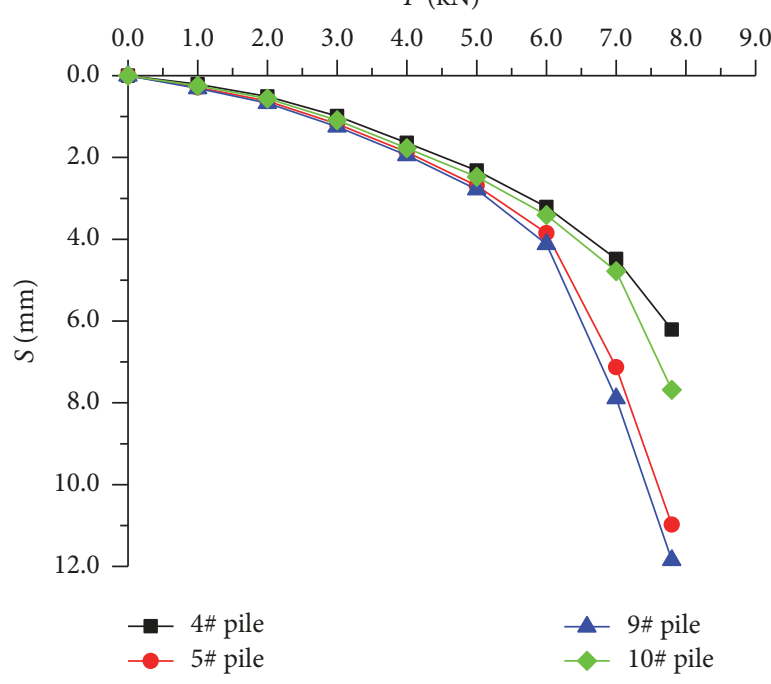

(b) Four-pile group

(a) Single pile

$$
F(\mathrm{kN})
$$

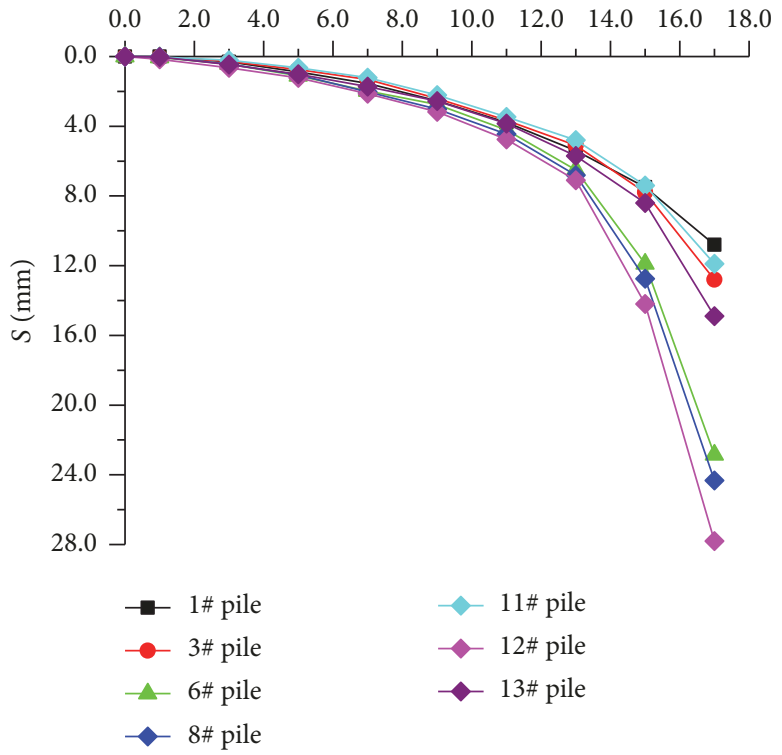

(c) Seven-pile group

Figure 5: Relations between the horizontal load $F$ and the displacement of the pile heads $S$ for the pile groups considered. 
Axial force $F(\mathrm{kN})$

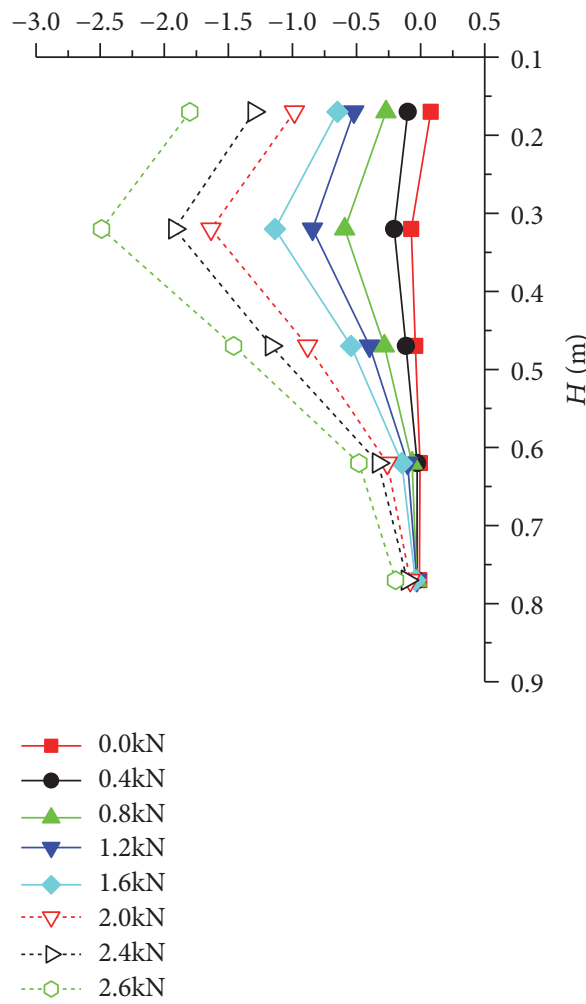

(a) \#2 pile (single pile)

Axial force $F(\mathrm{kN})$

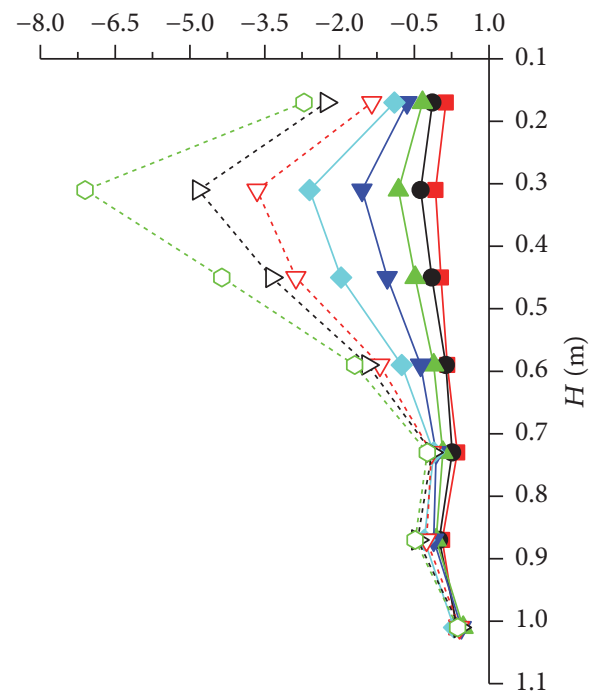

Axial force $F(\mathrm{kN})$

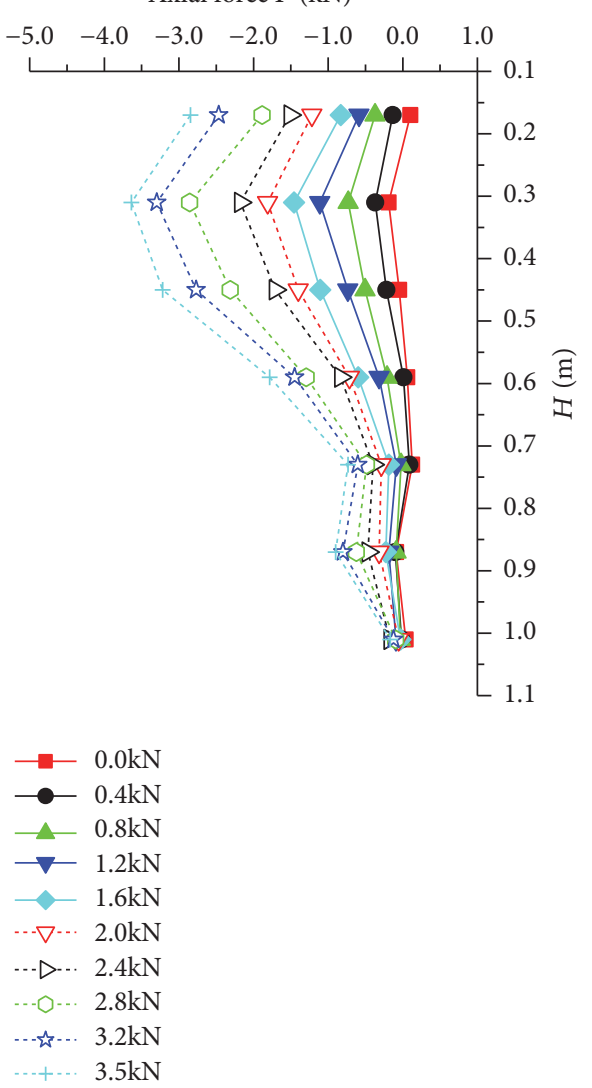

(b) \#7 pile (single pile)

Axial force $F(\mathrm{kN})$

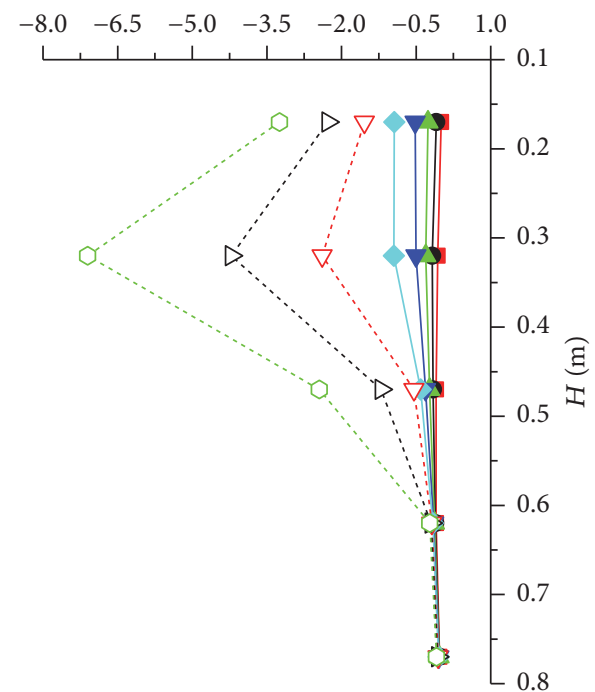

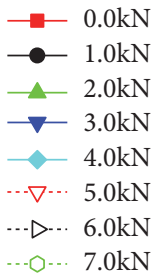

(c) \#5 pile (four-pile group)

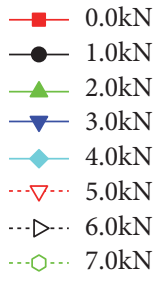

(d) \#10 pile (four-pile group)

Figure 6: Continued. 


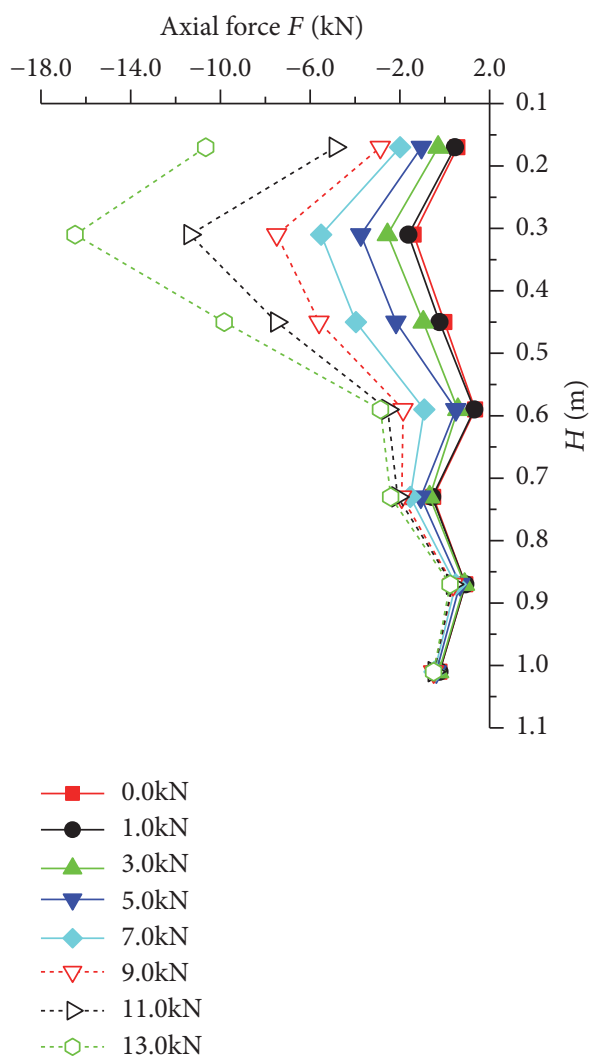

(e) \#1 pile (seven-pile group)

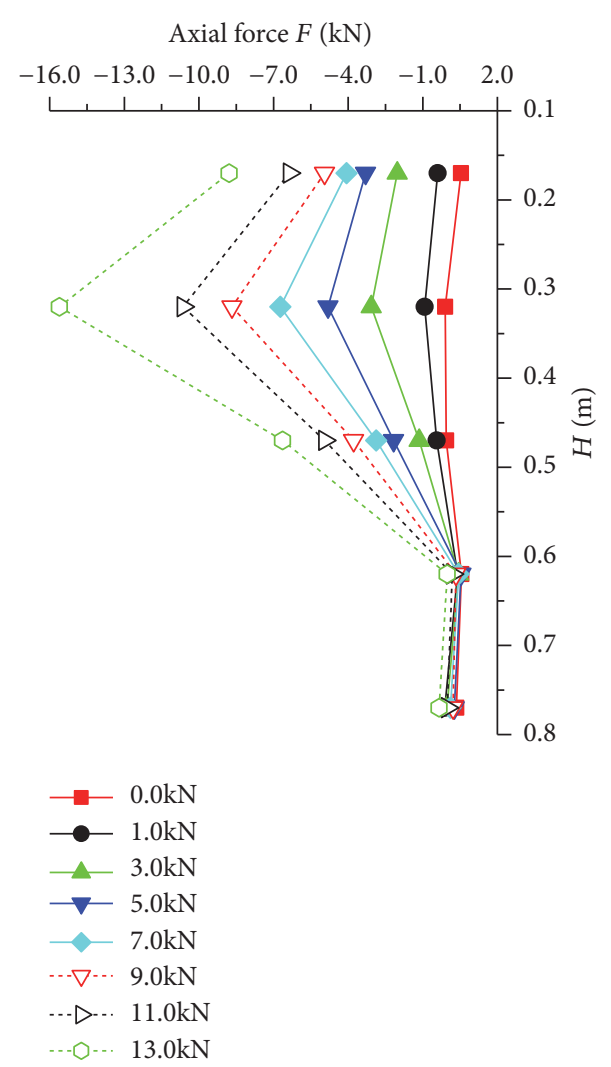

(f) \#8 pile (seven-pile group)

FIGURE 6: Relations between the axial forces acting on a pile with respect to location $\mathrm{H}$ along the length of the pile for various horizontal loads.

control the horizontal displacement, crack width limited, the deformation of the upper part of the pile foundation must be reduced by various measures such as increasing the pile reinforcement and improving the strength of the concrete.

3.2. Analysis of the Axial Force Acting on Test Piles with respect to Horizontal Load. Figure 6 presents the axial force distribution acting at the strain gauge locations $H(\mathrm{~m})$ along the lengths of the test piles for various horizontal loads. The figure shows that the axial forces increase with increasing horizontal force and that, during the early stages of loading, the horizontal loading at the pile head is mainly borne by the friction between the pile and surrounding soil near the top of the pile and type of friction pile. With the increasing load, the axial force increases, tending to end bearing pile. With increasing pile depth $\mathrm{H}$, the axial stress distributions of all short piles are very similar, and a peak value is observed at about $0.3 \mathrm{~m}$. Zero position of axial force constantly down shows that, the developed ability of axial force along pile length in the foundation is asynchronous.

These results differ from the axial force distribution of an in situ uniform loess foundation. Under in situ conditions, the vertical and horizontal loads are simultaneously brought to bear at the top of the pile. Moreover, the stiffness of pile end soil is small, and pile modulus is bigger. As a result, a stress concentration is easily produced, and the contact areas between the pile and surrounding soil gradually form a plastic zone. The upper portion of the pile body is firstly deformed and produced downward displacement of soil. The relative displacement between the pile and surrounding soil produces a frictional resistance at the pile-soil interface. The process of load transmission downwards along the pile body overcomes the frictional resistance, and in the diffusion process of passing it to the soil, which results in a decreasing axial force along the depth of the pile. The rate of attenuation in the axial force acting on the pile is not uniform. An increasing frictional resistance of the surrounding soil causes a more rapid decay in the axial force. This is equivalent to the change in the transverse compactness of the artificial layered fill employed in the model experiments.

Comparing the long and short piles under different horizontal loads, the long piles bear the majority of the load, but, because the length-diameter ratio is greater than that of the short piles, smaller stiffness and inflection appear, and the stress is more complicated. Compared with the single pile cases, the axial force distributions of the pile groups under the application of a horizontal force and transfer are more complicated and involve interactions between the piles and the soil surrounding the piles. The horizontal bearing capacity is related to strength of materials, the lateral resistance of the soil and foundation forms, and other factors. For example, 
$f(\mathrm{kPa})$

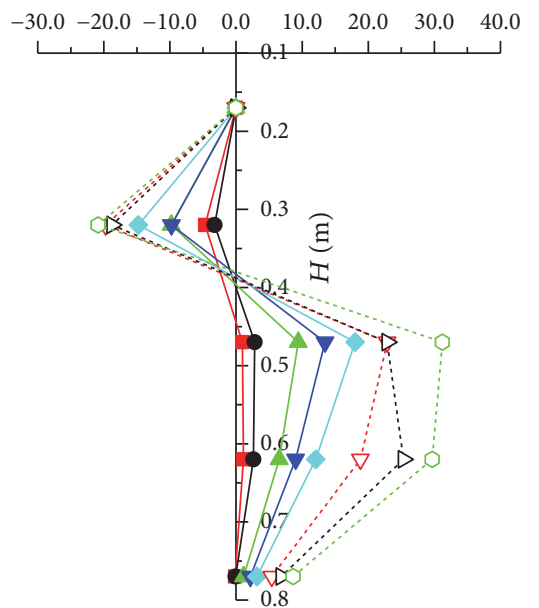

$-0.0 \mathrm{kN}$

$\longrightarrow 0.4 \mathrm{kN}$

$-0.8 \mathrm{kN}$

$\nabla-1.2 \mathrm{kN}$

$\longrightarrow 1.6 \mathrm{kN}$

$\cdots \nabla \cdots 2.0 \mathrm{kN}$

$\cdots \triangleright \cdots 2.4 \mathrm{kN}$

$\ldots-\ldots, 2.6 \mathrm{kN}$

(a) \#2 pile (single pile) $f(\mathrm{kPa})$

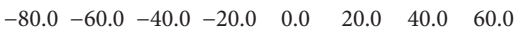
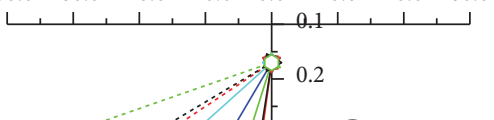

0

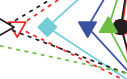

${ }_{0.4}^{0.3}$

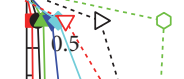

$20.6 \Rightarrow$
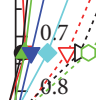

4.8

0.9

$[1.1$
$f(\mathrm{kPa})$

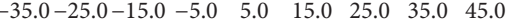
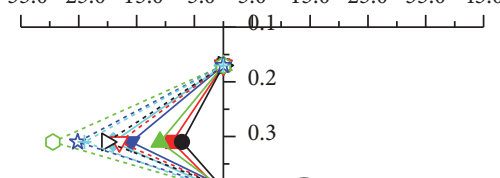

$0.4 \approx$
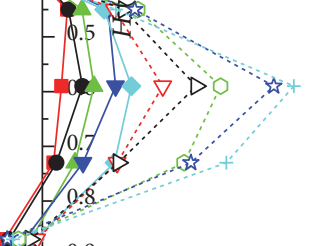

$\sqrt{ }$

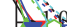

[1.1

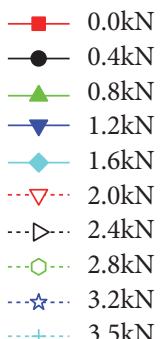

$\begin{array}{cc}\cdots & 3.2 \mathrm{kN} \\ \cdots & 3.5 \mathrm{kN}\end{array}$

(b) \#7 pile (single pile)
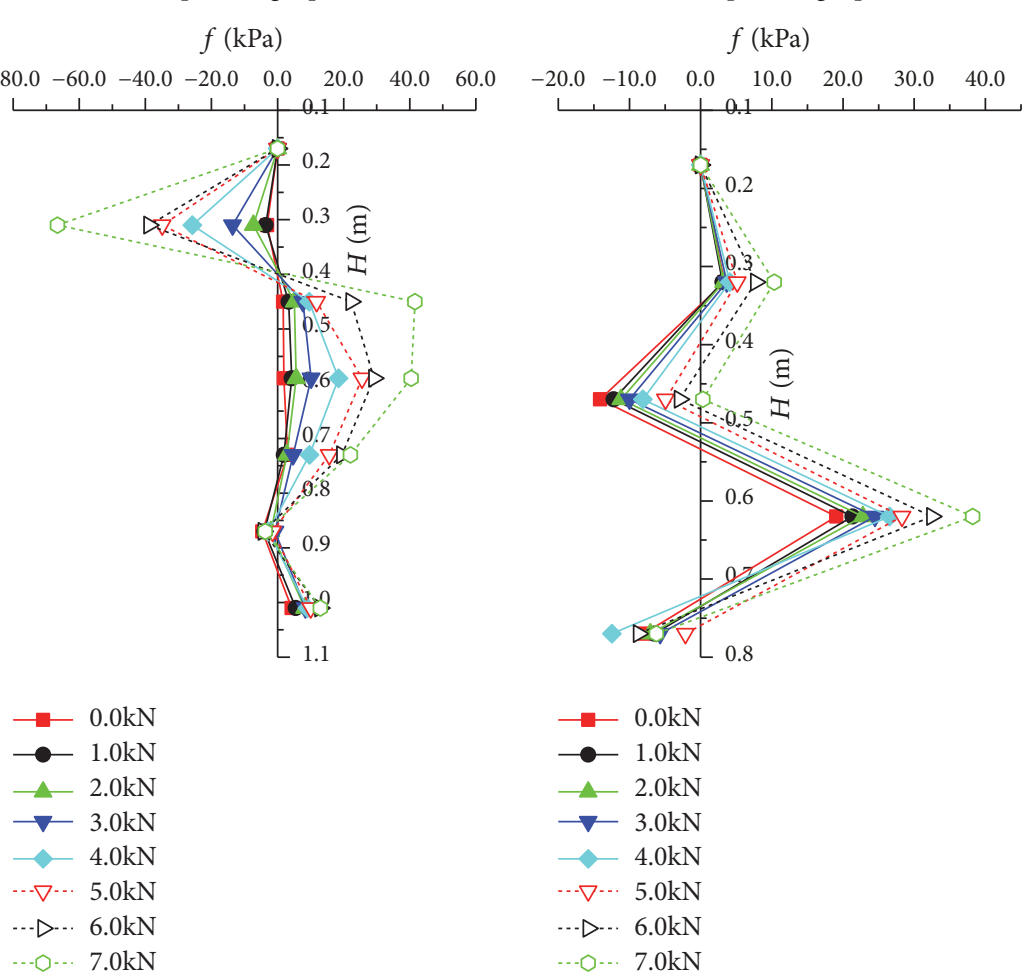

(c) \#5 pile (four-pile group) (d) \#10 pile (four-pile group)

FIGURE 7: Continued. 


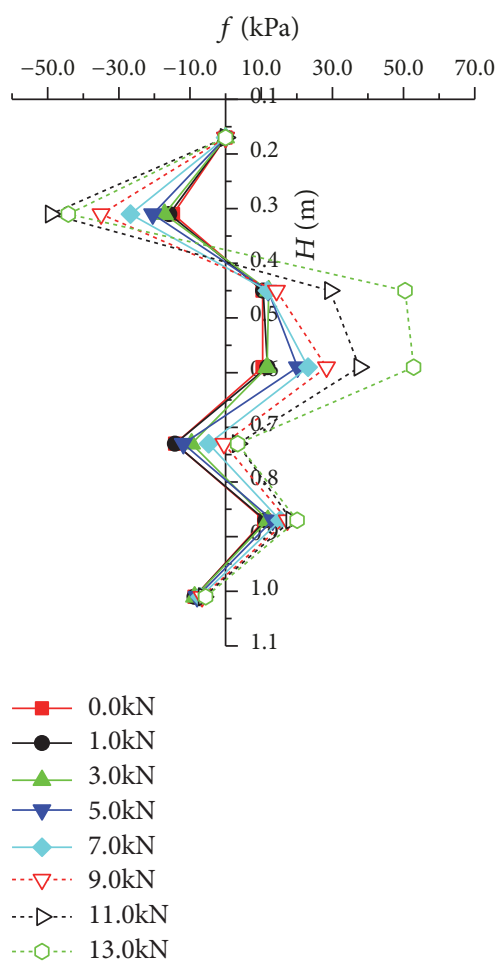

(e) \#1 pile (seven-pile group)

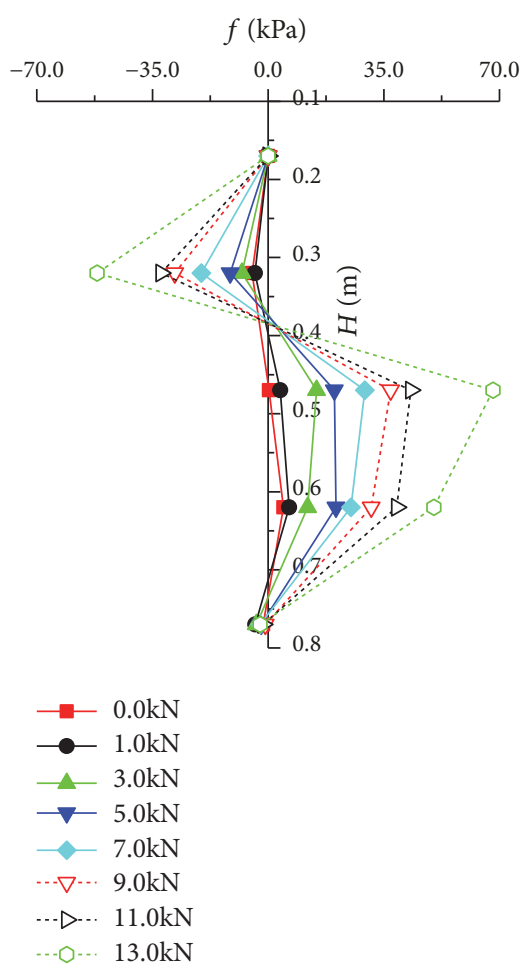

(f) \#8 pile (seven-pile group)

FIGURE 7: Relations reflecting the frictional resistance f between the piles and surrounding soil with respect to $\mathrm{H}$ for various horizontal loads.

because the tensile strength of concrete is far lower than its compressive strength, with increasing horizontal load, the pull part of the pile side appears fracture damage caused by a lack of tensile strength. Therefore, there is the possibility of cross-sectional tensile damage under the condition of small displacements and angle displacement.

\subsection{Analysis of Frictional Resistance between Test Piles and} Soil with respect to Depth under Different Horizontal Loads. Figure 7 shows the frictional resistance $f(\mathrm{kPa})$ between the test piles and the surrounding soil with respect to $H$ for different horizontal loads. The figure indicates the horizontal load in the process of transfer, the upper side of soil layer prior to resistance to the lower side of soil layer. With increasing horizontal load, the lateral resistance of the lower soil is gradually motivated, and the peak value of the distribution curve has a tendency to move downward gradually. A range of steep slow extent reflects the lateral resistance of the soil at a given depth. This is closely related to the degree of filling compaction, where the slope of the curve increases with a decreasing degree of soil compaction. As such, the slope of the curve is inversely related to the lateral resistance. The average value of $f$ for the various groups considered lies between $30 \mathrm{kPa}$ and $70 \mathrm{kPa}$. The position of maximum frictional force is $0.5 \mathrm{~m}$ to $0.7 \mathrm{~m}$. The magnitude of the negative frictional resistance and the position of neutral point are closely related to the process of water immersion, the process of consolidation settlement and pile top load, etc; for example, in the position of neutral point with the increase of immersion time down in Ningxia testing of ZH4 pile foundation, the positive and negative peak frictional resistance values increased. With increasing horizontal load in a saturated loading state, the settlement of the pile foundation is greater than that of the surrounding soil, and the neutral point moves upward sharply. However, with increasing horizontal load, the neutral point gradually moved upward, the positive frictional resistance increased, and the negative frictional resistance decreased. This indicates that the pile foundation would be costly if the neutral point position is calculated still according to the calculated thickness of collapsible soil layer. For very thick loess regions, short piles are placed on shallow supporting layers mainly to provide bearing capacity, and long piles are placed on deep supporting layers mainly to control the deformation of the pile foundation. This design conforms to the principle of a settlement-reducing pile.

In addition, although the magnitude of negative frictional resistance obtained from the test results is between 4 and $50 \mathrm{kPa}$, which is largely commensurate with the negative skin frictional resistance of collapsible loess obtained in field tests $(14.2-54.0 \mathrm{kPa})$, our results present at least two neutral points of pile. If we continue to apply the experience that the largest depth of neutral point is the bottom depth of collapsible loess, obviously, it does not accord with our findings here. The filled soil in model enclosure is distributed in sandwich layers interactively, whose collapsibility is discountinuous, which is same as the actual situation. Especially there is possibility that the non-collasiblity of large thickness loess layer changes to collapsiblity, which caused by the reshape of the surrounding soil, leading to compressive deformation by pile driving or 


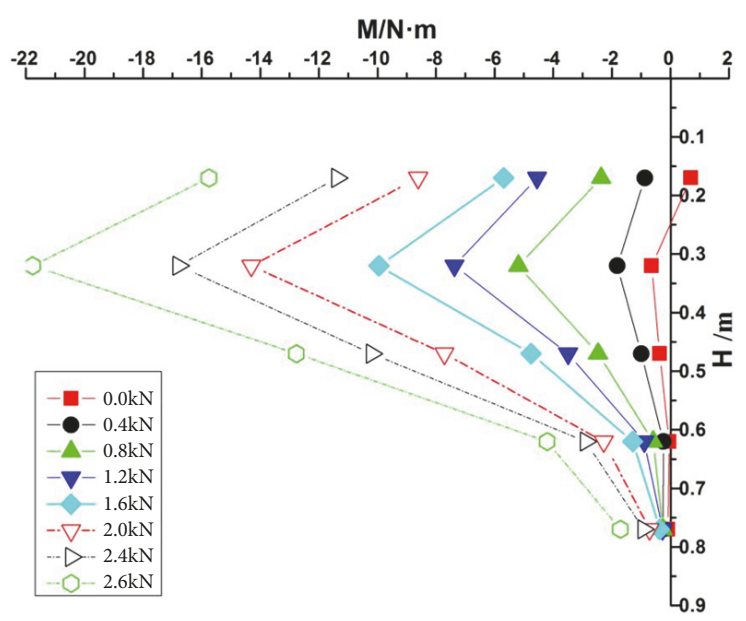

(a) \#2 pile (single pile)

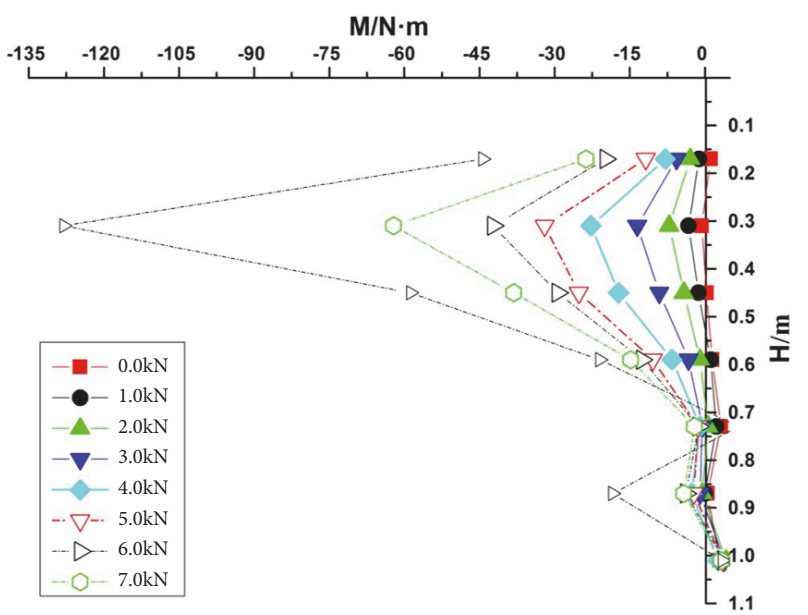

(c) \#5 pile (four-pile group)

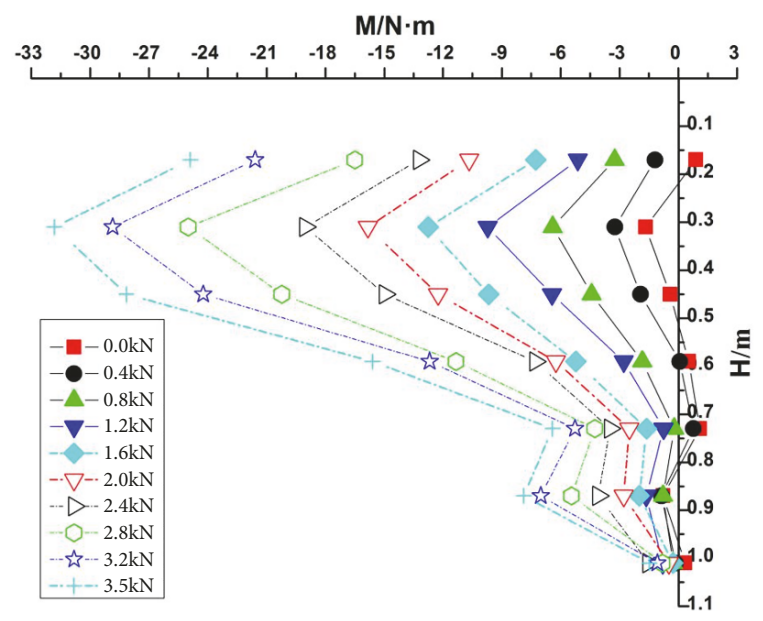

(b) \#7 pile (single pile)

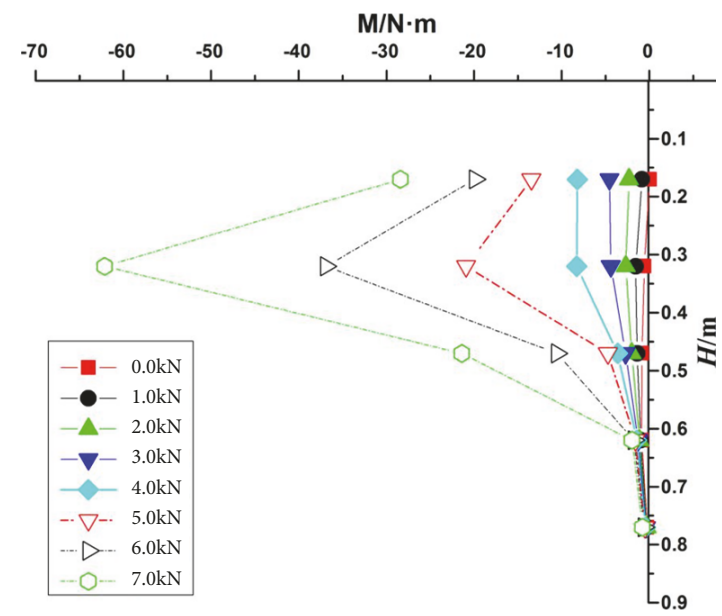

(d) \#10 pile (four-pile group)

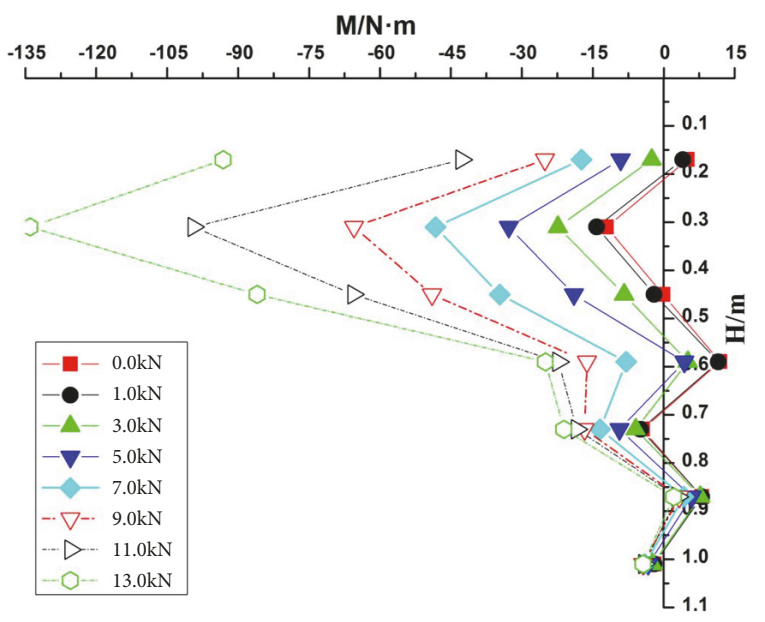

(e) \#1 pile (seven-pile group)

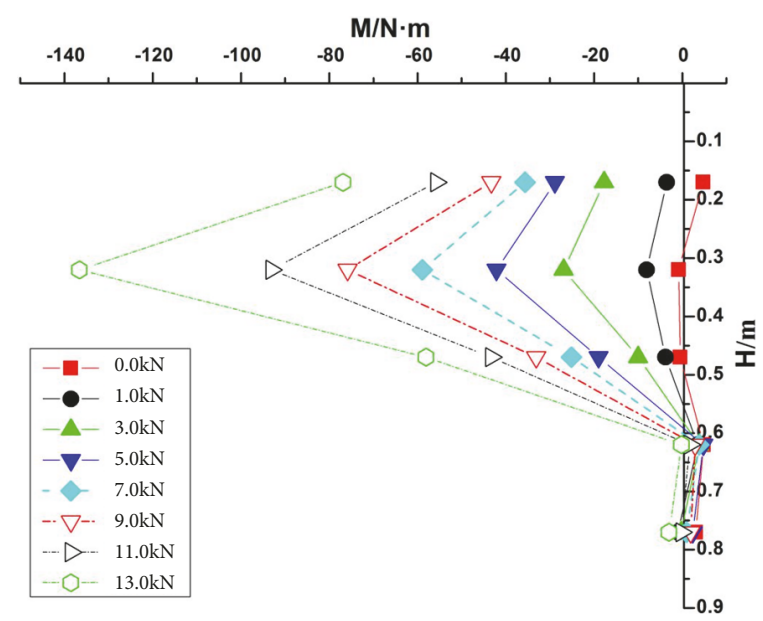

(f) \#8 pile (seven-pile group)

Figure 8: Moments along pile depth under the different horizontal load.

transmission of upper load. Therefore, pile lengths and pile foundation design should be taken seriously.

3.4. Analysis of the Moment Acting on Test Piles with respect to Depth under Different Horizontal Loads. According to the strain measured by the test, the moments of each section of the piles can be obtained by using the bending theory of material mechanics, as shown in Figure 8.

Figure 8 shows the moment's value is basically smaller on the top of the piles and larger at the middle and upper 


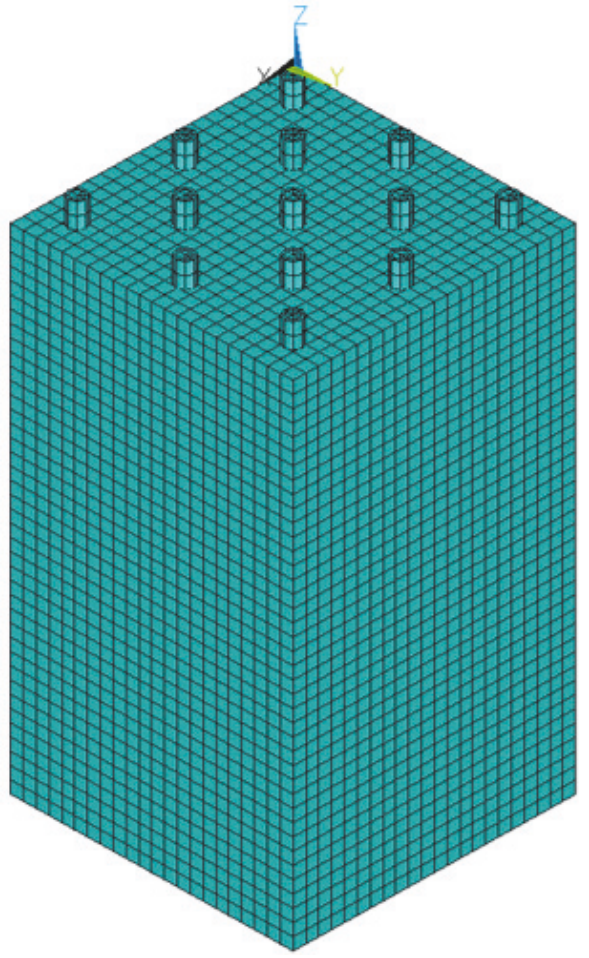

FIGURE 9: 3D model of the long-short pile composite foundation.

part of the piles. The moment of piles increases first and then decreases sharply with the pile depth, and the moment of pile approaches zero at the bottom of the piles, which shows the characteristics of flexible pile. The moment of the pile is approximately concentrated in the depth of $10 \mathrm{~d}(\mathrm{~d}$ is the diameter of the pile) below the top of the piles, and the maximum moment is located at the depth of (3-4)d of the piles. In the process of increasing horizontal load, the maximum moment of pile does not move down obviously, but the moment on the top of piles increases continuously. In addition, Figure 8 also proved that, most of the time, there are two neutral points in the pile at least. If the design of pile foundation is carried out according to the experience that the maximum depth of the neutral point is the lower limit depth of collapsible loess layer, it is inconsistent with the actual situation.

\section{Numerical Simulation Analysis}

4.1. The Finite Element Model. The composite pile foundation with long and short piles shown in Figure 4 was modeled in ANSYS 14.0 for conducting 3D elastic-plastic finite element analysis using equivalent pile lengths and diameters as those employed in the indoor test model; 3D model is shown in Figure 9. Piles were modeled as elastic Beam 188 elements (3D 2-Node Beam); but the soil was modeled using Solid 185 elements (3D 8-Node Structural Solid) in accordance with the Drucker-Prager yield criterion. Because the pile and the soil material parameters were substantially different, the contact surfaces were modeled using nonlinear shear
TABLE 2: Model parameters employed in finite element analysis.

\begin{tabular}{lccccc}
\hline & $E(\mathrm{MPa})$ & $\nu$ & $c(\mathrm{kPa})$ & $\varphi\left(^{\circ}\right)$ & $\gamma\left(\mathrm{kN} / \mathrm{m}^{3}\right)$ \\
\hline Pile & 30,000 & 0.2 & - & - & 2,600 \\
Soil layer & 70 & 0.34 & 35 & 24 & 1,700 \\
\hline
\end{tabular}

spring elements, which can overcome the errors associated with linear elastic model calculations [18]. The calculation domain was equivalent to that of the model enclosure in the horizontal direction and was $2 \mathrm{~m}$ high in the vertical direction. Piles were modeled using $0.05 \mathrm{~m}$ units and the soil was modeled using $0.05 \mathrm{~m} \times 0.05 \mathrm{~m} \times 0.05 \mathrm{~m}$ cubic units. Constraints were applied around all external sides of the model, except for the bottom, which was not constrained. The model parameters are listed in Table 2.

In the first step, only gravity was applied, without any other load. Then horizontal loading was separately applied to the single pile ( $\# 2$ or $\# 7$ ), four-pile group ( $\# 4, \# 5$, \#9, and $\# 10$ ), and nine-pile group (\#1-\#3, \#6-\#8, and \#11-\#13) for different conditions, when a vertical load was forced that was $80 \%$ of the ultimate bearing capacity of the piles.

\subsection{Analysis of Pile Body Strain and Displacement under} Different Horizontal Loads. The strain contours of pile bodies are shown in Figure 10 under the different horizontal loads. We note that the strain increases with increasing horizontal load, while the strain gradually decreases (i.e., the minimum strain point moves continuously downward) with increasing $\mathrm{H}$. Long piles exhibit regions of negative bending because of their lower stiffness and bear the majority of the horizontal load. Single piles \#2 and \#7 both present $\mathrm{S}$ values of 2.8 and $5.0 \mathrm{~mm}$ at horizontal loads of 2.65 and $3.49 \mathrm{kN}$, respectively, which are in good agreement with the static load test results. This indicates that the numerical analyses can accurately represent the F-S relationships obtained under experimental conditions, and represents a useful tool in engineering design. For the four-pile and nine-pile groups, the maximum values of $\mathrm{S}$ obtained under a horizontal load of $15 \mathrm{kN}$ were 5.6 and $10 \mathrm{~mm}$, respectively. For the four-pile group, the maximum strain was obtained on the short piles, and the soil between piles in the central pile (\#7) strain was greater than that of the peripheral piles (\#6 and \#8). For the nine-pile group, the piles residing in the corners (\#1, \#3, \#11, and \#13) exhibit no obvious displacements, which is not consistent with standard pile foundation theory and the pile foundation test results. This may have been caused by the test of the pile head adjusted uneven and eccentric loading. As was observed for the four-pile group, the maximum strain was also obtained for the short piles of the nine-pile group ( $\# 2, \# 6$, \#8, and \#12), which verifies the conclusion obtained from the experimental results that short piles experience greater deformation and damage before the long piles in a composite pile foundation. The strain in upper part of $\# 4, \# 5$, \#9, and \#10 piles is obvious. In conclusion, the strain of piles is mainly concentrated from the pile head to about a third of the maximum $\mathrm{H}$. On a certain point in a pile, the pile body will rotate about its longitudinal axis, and the integrity of the pile foundation will be reduced to below acceptable limits when $S$ becomes too large. For the 


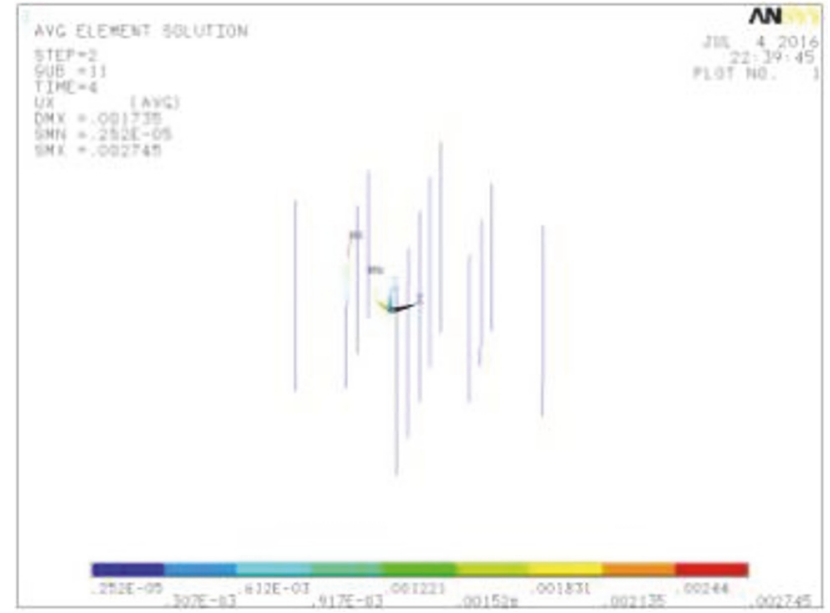

(a) \#2 single pile

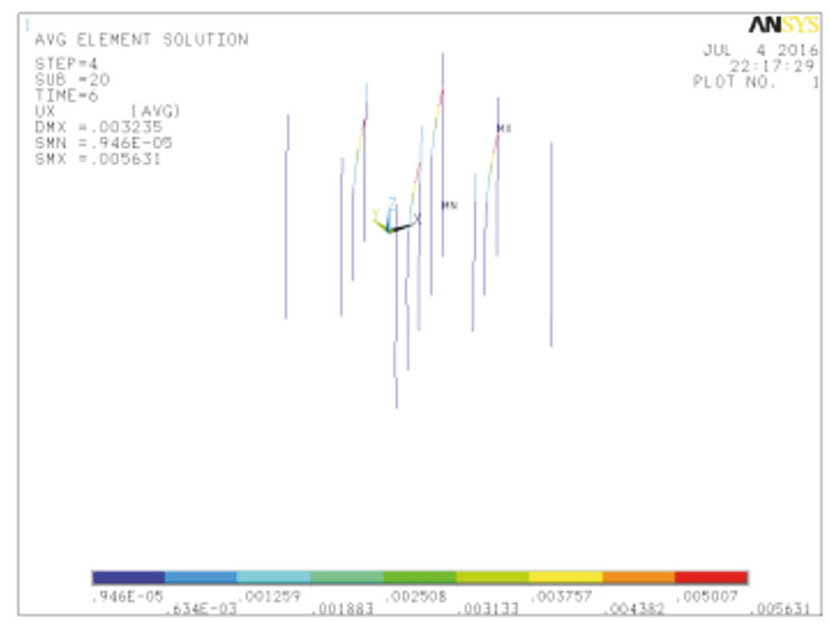

(c) Four-pile group

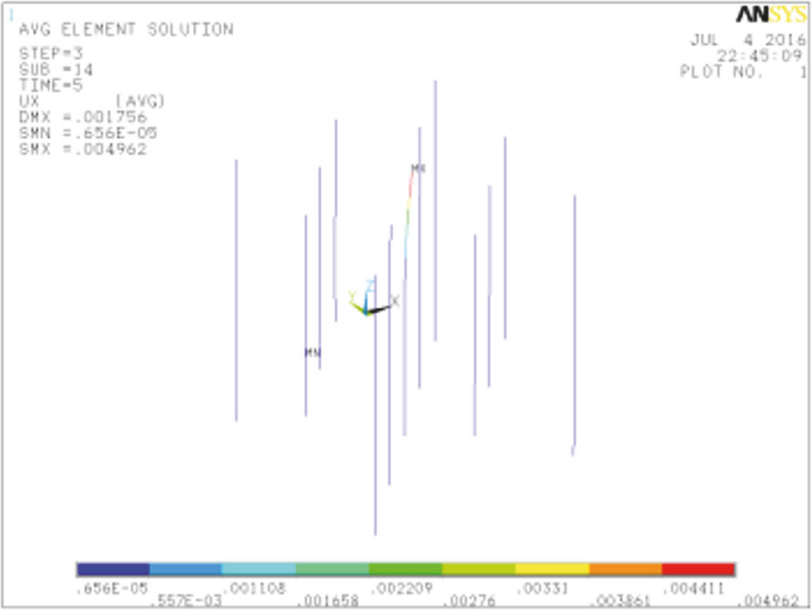

(b) \#7 single pile

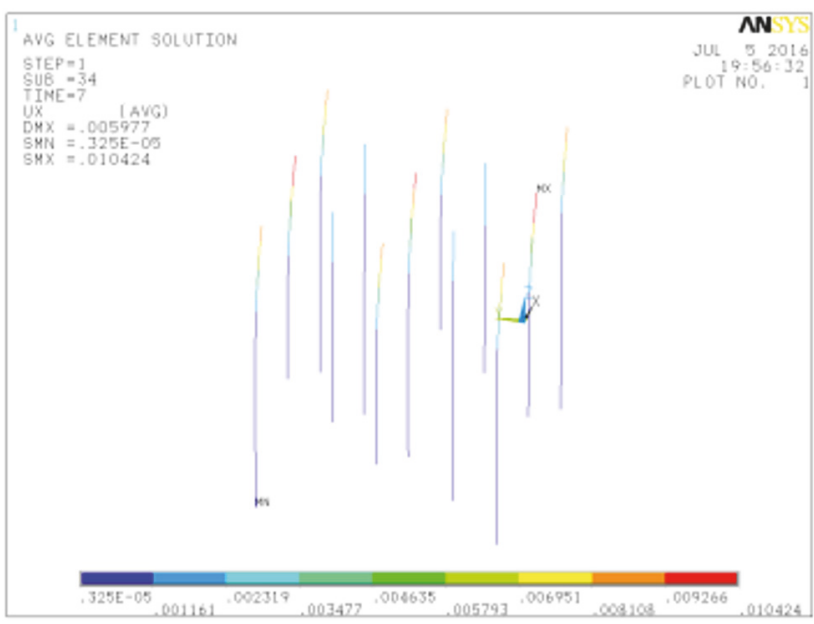

(d) Nine-pile group

FIGURE 10: Strain nephograms of piles under different horizontal loads.

long piles, the pile bodies undergo flexural deformation, and the pile body will suffer damage due to bending when the pile body displacement and bending moment increase beyond acceptable limits.

Owing to space limitations, we examine the displacement $S$ with respect to $H$ under different horizontal loads for only the nine-pile group in detail. As shown in Figures 11(a) and 11(b), the values of $S$ for \#1 and \#8 pile bodies gradually increase with increasing horizontal load, and the values of $S$ rapidly decrease with increasing $H$, and both exhibit a point of zero displacement. For long pile \#1, the first point of zero displacement occurs at $H=0.4 \mathrm{~m}$, and the second point of zero displacement occurs near the bottom of the pile. The magnitude of the negative displacement obviously increases with increasing horizontal load, and the second point of zero displacement moves downward continuously. If the material strength of the pile is increased, the horizontal bearing capacity of pile foundation is controlled by the displacement. For short pile \#8, the displacement is small, but, because the pile under section is not fully built-in, pile around the pile body rotates about midpoint with increasing horizontal load. With further increase in the horizontal load, the soil surrounding the pile begins to undergo local shear deformation due to a lack of shear strength and subsequently yields. The yield zone moves continuously downward until the surrounding soil suffers shear failure, which resulted in an excessively large foundation displacement, and damage to the soil at the base. Figure 11(c) shows that the relationship between the pile top displacement and horizontal load of numerical simulation and that of model tests has good consistency. At the same time, it also proved the rationality of the recommendation made in section 3.1 that a horizontal displacement limit of the pile foundation is $10 \mathrm{~mm}$ and $6 \mathrm{~mm}$ for the ones sensitive to horizontal displacement.

In conclusion, the material strength of the individual piles was eventually exceeded by the applied horizontal loading and produced lateral deformation. The interplay of lateral forces between the piles and their surrounding soil represents a complex interaction. As pile body deformation gradually increases with increasing horizontal load, the stress 

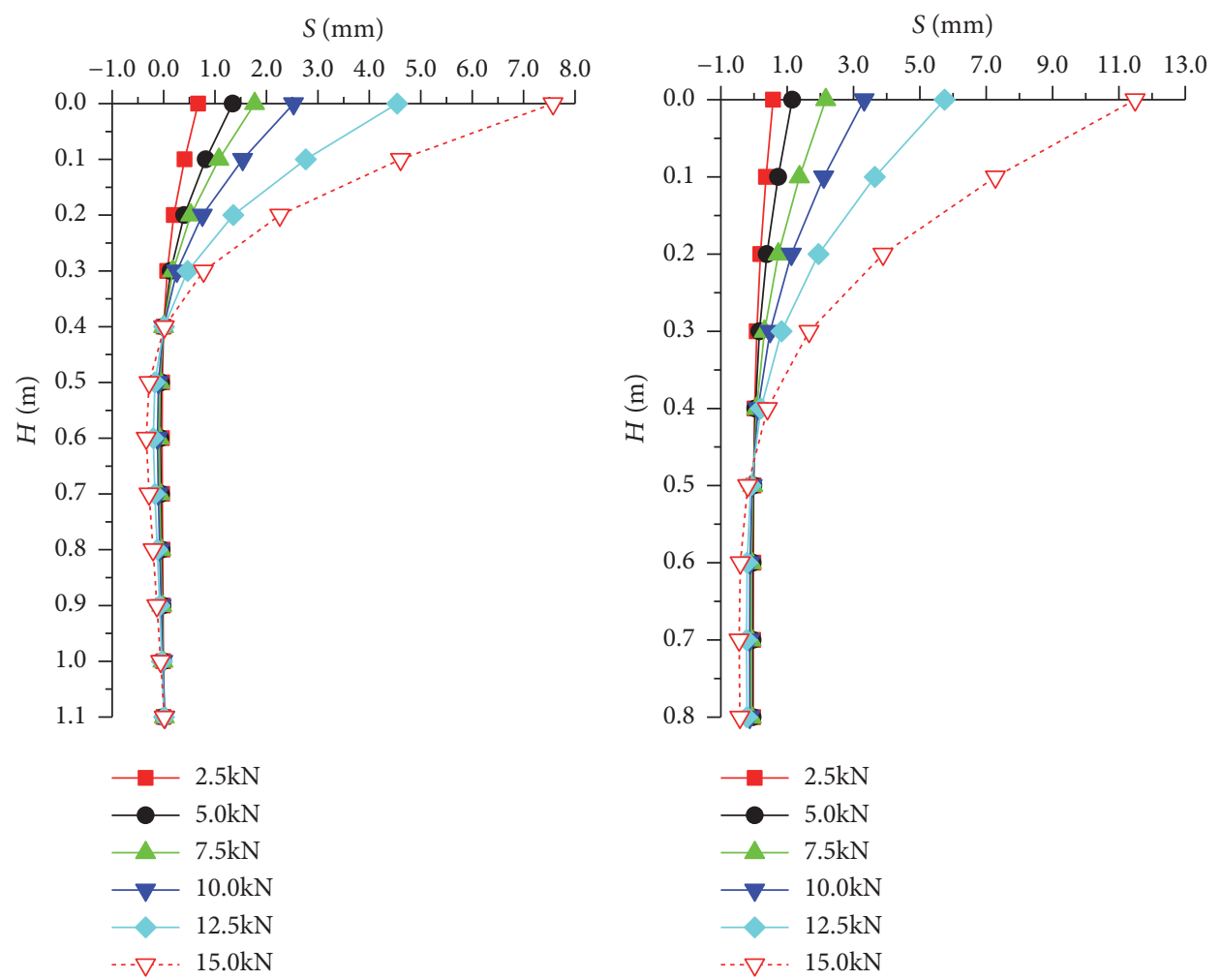

(a) \#1 pile

(b) \#8 pile

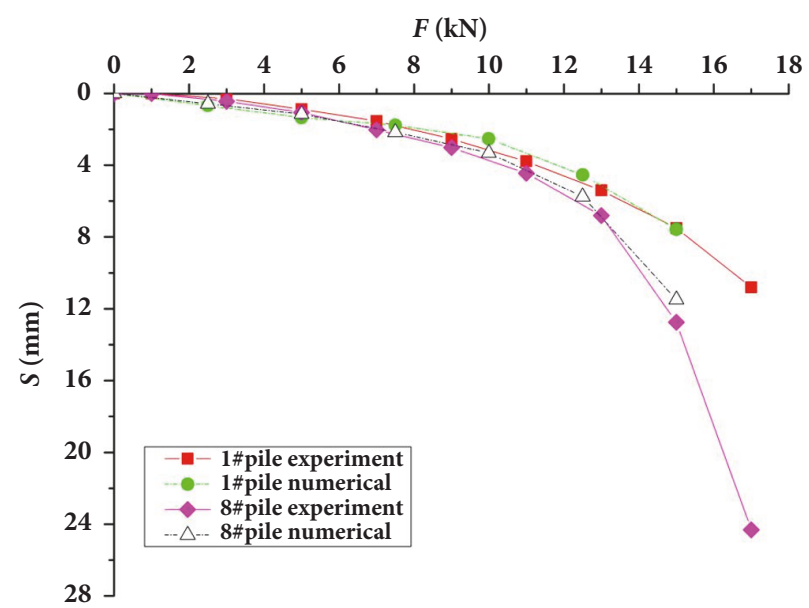

(c) Displacement comparison of pile between the numerical and experimental results

FIGURE 11: Displacement $S$ with respect to $H$ for the nine-pile group under different horizontal loads.

eventually exceeds the allowable limit or the surrounding soil loses its stability and yields. Even if the pile body strength was sufficient to accommodate the high-stress conditions, the loss of soil stability or pile displacement exceeding specifications would lead to pile foundation damage. Therefore, the horizontal bearing capacity is mainly controlled by the strength of the soil surrounding the piles or the extent of horizontal displacement of the pile head, which are more likely to occur in areas prone to collapsible loess. All these factors should be considered in the design, construction, and use of composite pile foundations with short and long piles.

4.3. Analysis of Pile Body Stress and Axial Force under Different Horizontal Loads. Figure 12 presents stress nephograms of the pile groups under different horizontal loads. Owing to space limitations, we examine the axial force with respect to $H$ under different horizontal loads for only the nine-pile group in detail, as shown in Figure 13. We note that the maximum axial stress in Figure 12 was not obtained at the 


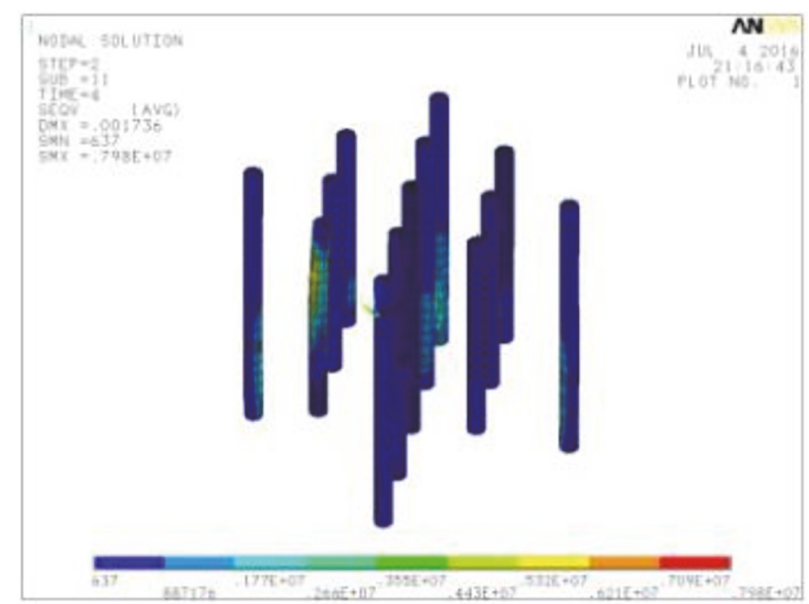

(a) \#2 single pile

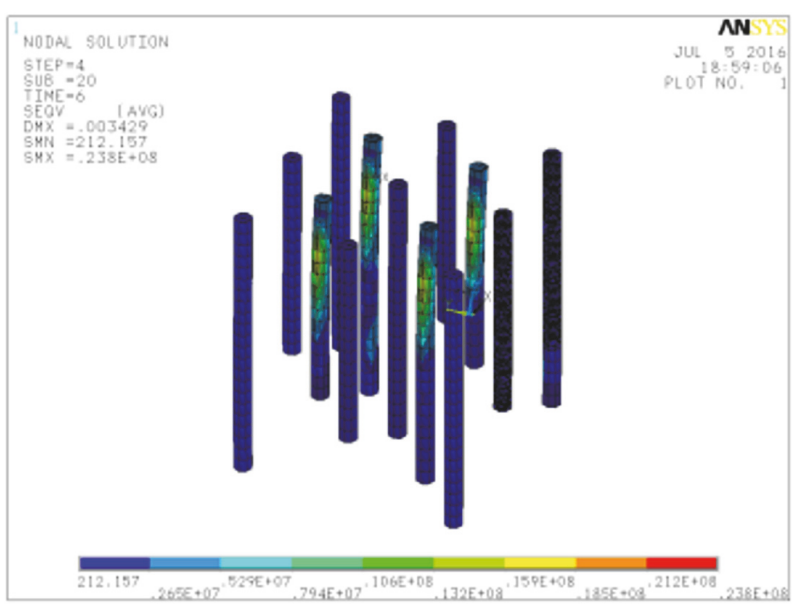

(c) Four-pile group

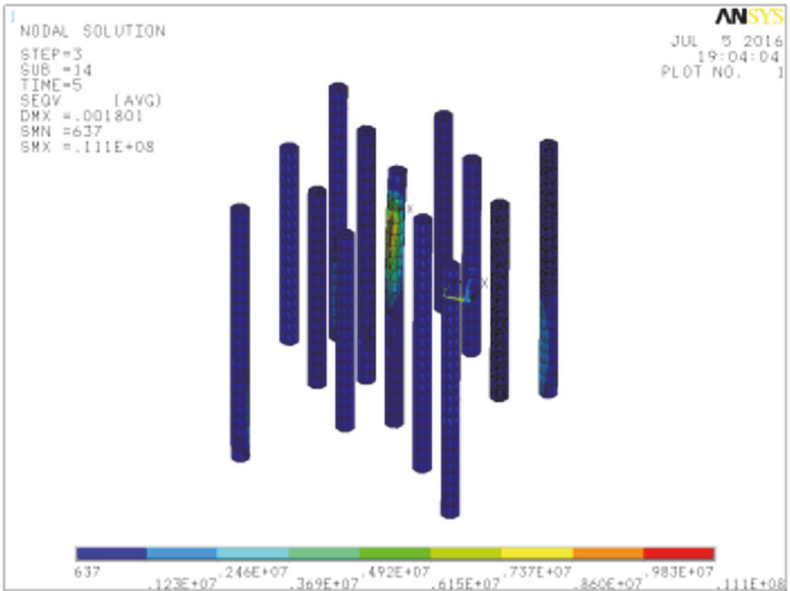

(b) \#7 single pile

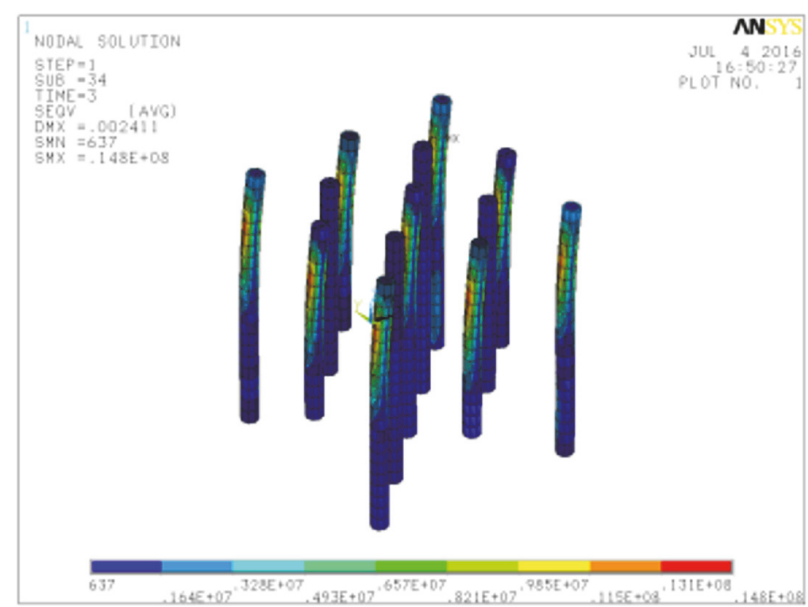

(d) Nine-pile group

FIGURE 12: Stress nephograms of piles under different horizontal loads.

pile head position, but some distance below the pile head for both long and short piles. These stress concentrations are formed when simultaneously applying vertical and horizontal loads because the elastic modulus of the piles is large. Here, the top soil layer surrounding the piles undergoes plastic deformation, which allows relatively easy pile displacement near the head, caused by pile on top of a certain depth range; displacement of soil mass is greater than the displacement of the pile, producing negative frictional resistance areas. As previously established, a negative skin frictional resistance above the neutral point makes the axial stress of the pile greater with increasing $H$, and, below the neutral point, the pile axial stress decays rapidly with increasing $H$ owing to the frictional resistance of the surrounding soil. Near the neutral point, the pile axial force attains a maximum value, as shown in Figure 13.

The results in Figures 13(a) and 13(b) show the maximum axial force occurs near the pile head, and at least two points of zero axial force are observed. The axial force distribution is similar to an "s" type distribution, whereas that of the short pile (\#8) is similar to an "s" type distribution. Stress areas in soil and plastic zone mainly range in the upper shallow soil (the stress diagram of foundation soil is abbreviated). A collapsible loess region improves the engineering properties of shallow soil layers and it not only can prevent the wet fall under the influence of water, but also can improve the horizontal bearing capacity of a pile foundation. \#1 long pile deflection, \#8 short pile in the overall rotation, with increasing horizontal loading, the axial force near the pile bottom can significantly increase, and, near the pile head, the amplitude of the axial force increases less rapidly with decreasing $H$. The load above a certain depth increment will be negligible, which can provide a reference for pile length design. It must be pointed out that, according to Figures 13(c) and 13(d), the results of the numerical simulation are basically consistent with those of the indoor model test, but because the indoor test conditions are difficult to achieve the ideal conditions of the numerical simulation, there are still some differences between the two results. 

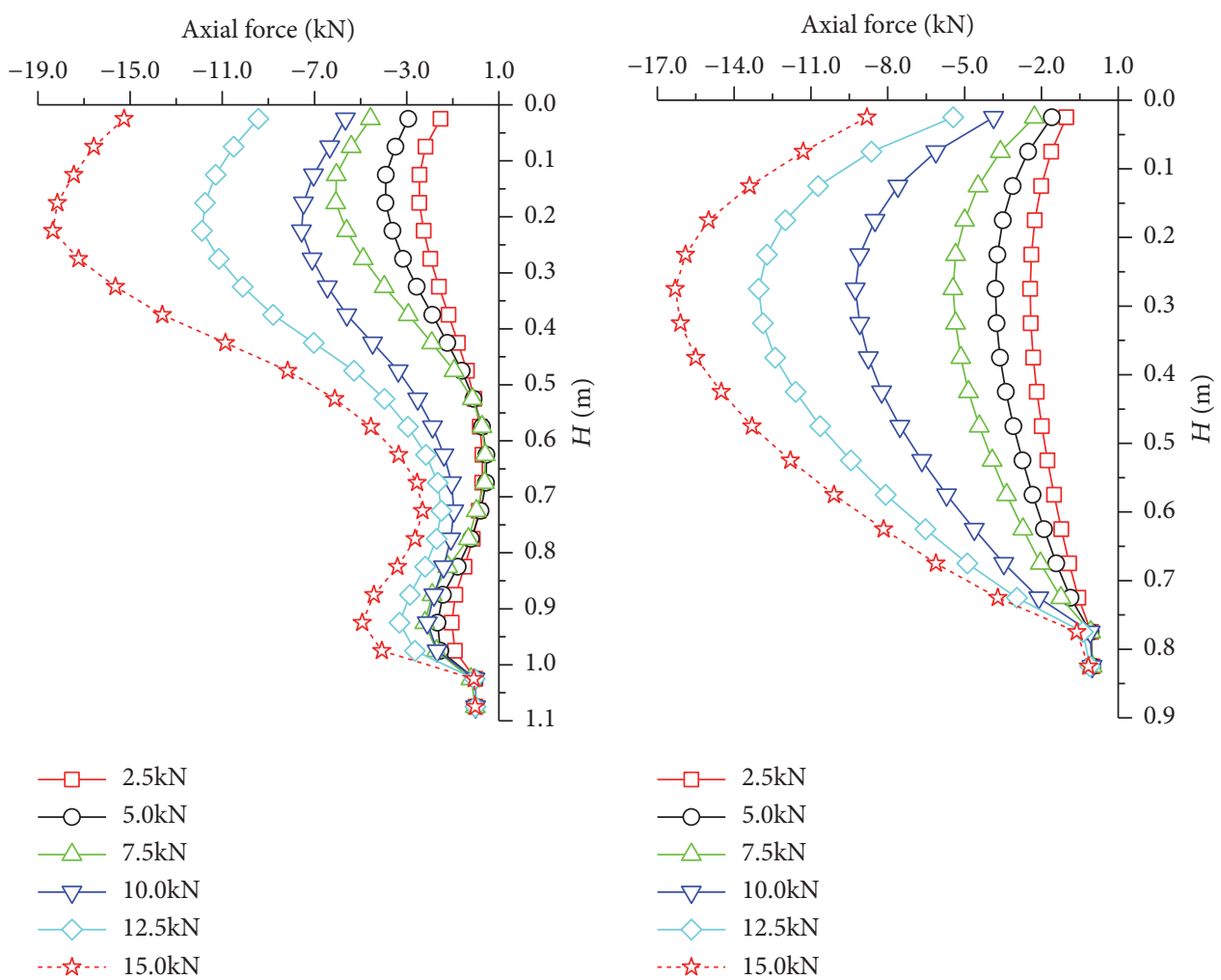

(a) \#1 pile

(b) \#8 pile

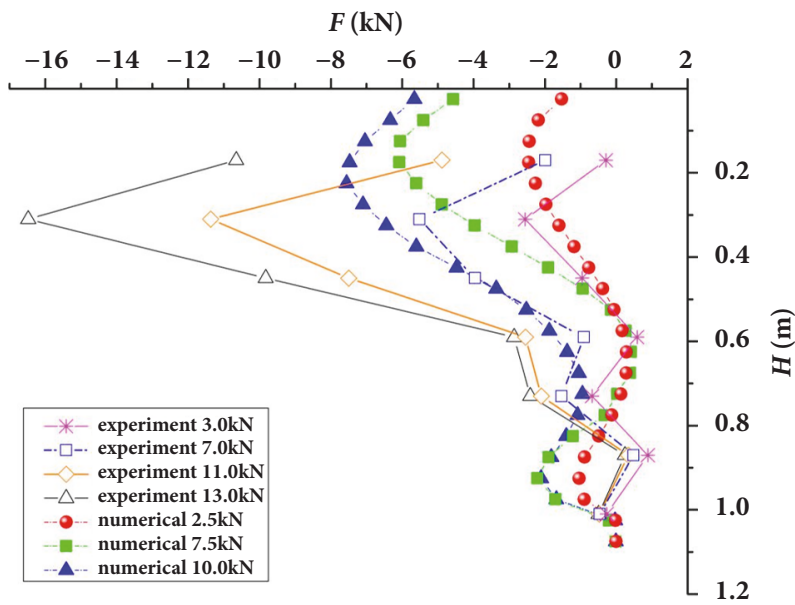

(c) Axial comparison of Pile 1 between the numerical and experimental results

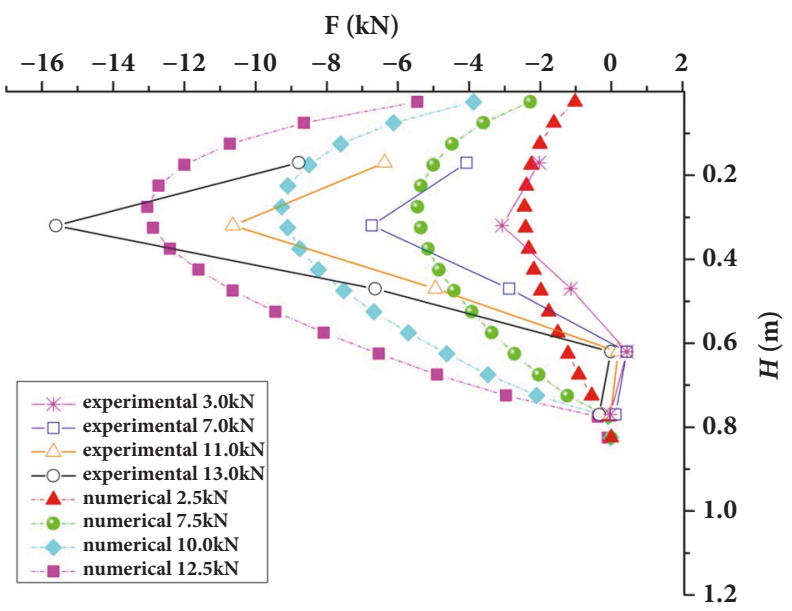

(d) Axial comparison of Pile 8 between the numerical and experimental results

Figure 13: Axial force distribution with respect to $\mathrm{H}$ for the nine-pile group under different horizontal loads.

\section{Conclusions}

(1) Under the application of different horizontal loads, the F$S$ curves of the pile foundation exhibited an obvious steep fall in the section, which is a typical feature of piercing damage. Short piles were observed to suffer damage with increasing horizontal loading prior to long piles. A horizontal displacement limit of the pile foundation is $10 \mathrm{~mm}$ and $6 \mathrm{~mm}$ for the ones sensitive to horizontal displacement.
(2) The play of pile axial force and pile-soil interfacial frictional resistance with asynchrony: the pile-soil interfacial frictional resistance under different horizontal loads ranged from $30 \mathrm{kPa}$ to $70 \mathrm{kPa}$. The magnitude of the negative skin frictional resistance ranged between 4 and $50 \mathrm{kPa}$. There are multiple nuetral points along pile bodies because the soil interlayers surrounding piles distribute interactively and the distribution of collapsibility is discountinous, which leads to the determination of the lower limit depth is complex in collapsible soil layer. So the design thought applying 
long-short composite pile foundation conforms to the principle of settlement reducing pile.

(3) Pile body stress and strain are mainly concentrated between the pile head and about one-third of the pile depth. Beginning at a particular depth along a short pile, the pile body will rotate about its longitudinal axis, and the integrity of the pile foundation will be reduced to below acceptable limits when the displacement becomes too large. For the long piles, the pile bodies undergo flexural deformation, and the pile body will suffer damage due to bending when the pile body displacement and bending moment increase beyond acceptable limits. The horizontal bearing capacity is mainly controlled by the strength of the soil surrounding the piles or the extent of horizontal displacement of the pile heads.

(4) The finite element analysis results of the pile foundation were in good agreement with the results of the experimental model testing. Especially the pile-soil contact surface is simulated with nonlinear shear spring elements, which can provide a useful example for future engineering design.

\section{Data Availability}

The data used to support the findings of this study are available from the corresponding author upon request.

\section{Conflicts of Interest}

The authors declare that they have no financial and personal relationships with other people or organizations that can inappropriately influence their work; there is no professional or other personal interest of any nature or kind in any product, service, and/or company that could be construed as influencing the position presented in, or the review of, the paper entitled.

\section{Acknowledgments}

This work was supported by the National Science Foundation of China "Theoretical analysis and testing study on row pile supporting with pre-stressed anchors for deep foundation pit" (No. 51568042) and Program for Changjiang Scholars and Innovative Research Team in University (No. IRT_17R51). We thank LetPub (www.letpub.com) for its linguistic assistance during the preparation of this manuscript.

\section{Supplementary Materials}

Supplementary Materials description: 1, e.g., \#5: relations between the horizontal load $\mathrm{F}$ and the displacement of the pile heads $\mathrm{S}$ for the pile groups considered. 2, e.g., \#6: relations between the axial forces acting on a pile with respect to location $\mathrm{H}$ along the length of the pile for various horizontal loads. 3, e.g., \#7: relations reflecting the frictional resistance $\mathrm{f}$ between the piles and surrounding soil with respect to $\mathrm{H}$ for various horizontal loads. 4, Fig. 10: displacement S with respect to $\mathrm{H}$ for the nine-pile group under different horizontal loads. 5, e.g., \#12: axial force distribution with respect to
$\mathrm{H}$ for the nine-pile group under different horizontal loads. (Supplementary Materials)

\section{References}

[1] Y. J. Teng, W. D. Wang, and J. W. Kang, "The new development of the technology of building foundation engineering," in Proceedings of the set of academic paper of the national soil mechanics and geotechnical engineering in 12th, pp. 66-95, Shanghai, China, 2015.

[2] X. Zhao, Q. Zhang, and B. Zhang, "Iterative method for calculating the settlement of pile foundation with negative friction," Yantu Lixue/Rock and Soil Mechanics, vol. 20, no. 2, pp. 17-21, 1999.

[3] D. Z. Li, Y. J. Teng, and Y. H. He, "Vertical bearing behaviour of large diameter belled pile in collapse loess," Chinese Journal of Geotechnical Engineering, vol. 16, no. 2, pp. 11-21, 1994.

[4] S. J. Feng, H. Ke, and Y. H. Chen, "Experimental study on super long bored pile in loess," Chinese Journal of Geotechnical Engineering, vol. 26, no. 1, pp. 110-114, 2004.

[5] X. F. Huang, Z. H. Chen, and S. Ha, "Research on bearing behaviors and negative friction force for filling piles in the site of collapsible loess with big thickness," Chinese Journal of Geotechnical Engineering, vol. 29, no. 3, pp. 338-346, 2007.

[6] Y. P. Zhu, T. S. Zhao, and C. L. Chen, "Field tests on changes of pile negative friction along its length," Rock and Soil Mechanics, vol. 34, no. S1, pp. 265-272, 2013.

[7] J. G. Zheng, G. H. Deng, and Z. H. Liu, "Influence of discontinuous distribution of collapsible loess on its deformation," Chinese Journal of Geotechnical Engineering, vol. 37, no. 1, pp. 165-170, 2015.

[8] X. Yang, X. Huang, Y. Zhu, Z. Yao, and S. Zhang, "Experimental study on collapsibility evaluation and treatment depths of collapsible loess upon self weight with thick depth," Yanshilixue Yu Gongcheng Xuebao/Chinese Journal of Rock Mechanics and Engineering, vol. 33, no. 5, pp. 1063-1074, 2014.

[9] M. Yang, H. Yang, and W. Wang, "Design philosophy and settlement analysis of the composite long-short pile foundations," China civil engineering journal, vol. 38, no. 12, pp. 103-108, 2005.

[10] F. Liang, L. Chen, and J. Han, "Integral equation method for analysis of piled rafts with dissimilar piles under vertical loading," Computers \& Geosciences, vol. 36, no. 3, pp. 419-426, 2009.

[11] S. C. Wong and H. G. Poulos, "Approximate pile-to-pile interaction factors between two dissimilar piles," Computers \& Geosciences, vol. 32, no. 8, pp. 613-618, 2005.

[12] Y. F. Leung, A. Klar, and K. Soga, "Theoretical study on pile length optimization of pile groups and piled rafts," Journal of Geotechnical and Geoenvironmental Engineering, vol. 136, no. 2, pp. 319-330, 2010.

[13] Z. J. Wang, X. Y. Xie, and P. F. Fang, "Analysis for calculation of nonlinear settlement of rigid long-short compound piles," Journal of Zhejiang University (Engineering Science), vol. 48, no. 3, pp. 463-470, 2014.

[14] J. Xiong, F. Li, X. Zhu, and M. Yang, "Model test of composite long-short pile foundation," Tongji Daxue Xuebao/Journal of Tongji University, vol. 36, no. 10, pp. 1337-1343, 2008.

[15] M. Huang, B. Li, and Y. Cheng, "Centrifuge model tests and numerical simulation of load sharing law for composite embankment with long and short piles," Yanshilixue Yu Gongcheng Xuebao/Chinese Journal of Rock Mechanics and Engineering, vol. 29, no. 12, pp. 2543-2550, 2010. 
[16] X. N. Ma, S. Z. Li, and Z. B. Tian, "Research on the Deformation and Bearing Characteristics of Composite Foundation with Long and Short Piles," Journal of Railway Engineering Society, vol. 3, pp. 6-11, 2016.

[17] D. A. Brown and C.-F. Shie, "Some numerical experiments with a three dimensional finite element model of a laterally loaded pile," Computers \& Geosciences, vol. 12, no. 2, pp. 149-162, 1991.

[18] X. S. Ge, X. N. Gong, and X. M. Zhang, "FEM analysis and design of long-short-pile composite foundation," Journal of Building Structures, vol. 24, no. 4, pp. 91-96, 2003.

[19] M. Achmus and K. Thieken, "On the behavior of piles in noncohesive soil under combined horizontal and vertical loading," Acta Geotechnica, vol. 5, no. 3, pp. 199-210, 2010.

[20] H. H. Zhang and J. C. Small, "Analysis of capped pile groups subjected to horizontal and vertical loads," Computers \& Geosciences, vol. 26, no. 1, pp. 1-21, 2000.

[21] L. Zhang, M. Zhao, and X. Zou, "Behavior of Laterally Loaded Piles in Multilayered Soils," International Journal of Geomechanics, vol. 15, no. 2, pp. 1-7, 2015. 


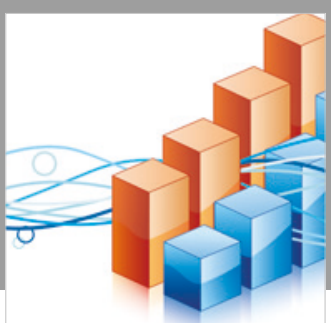

Advances in

Operations Research

\section{-n-m}
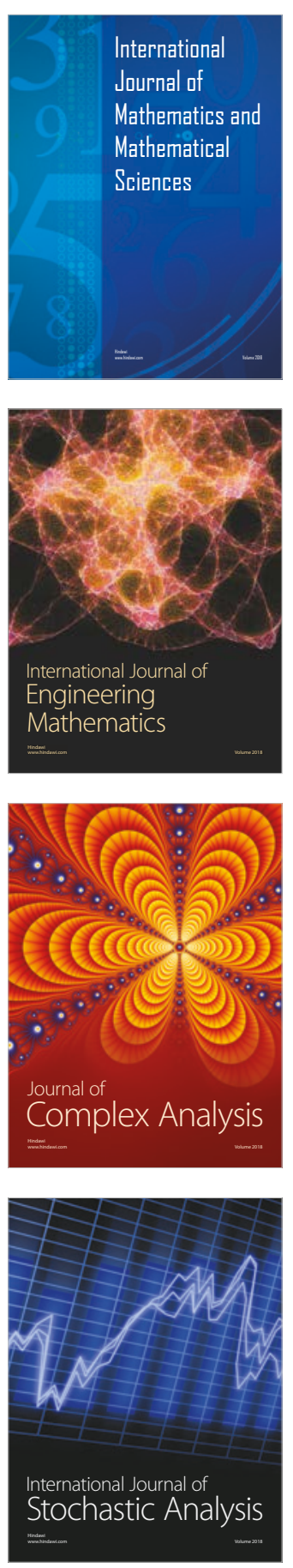
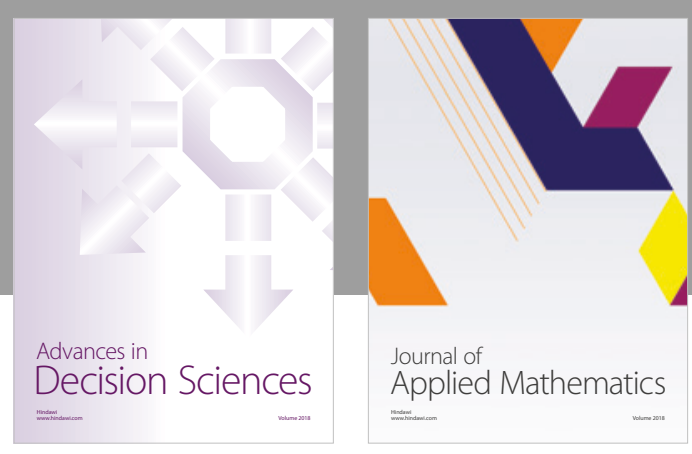

Journal of

Applied Mathematics
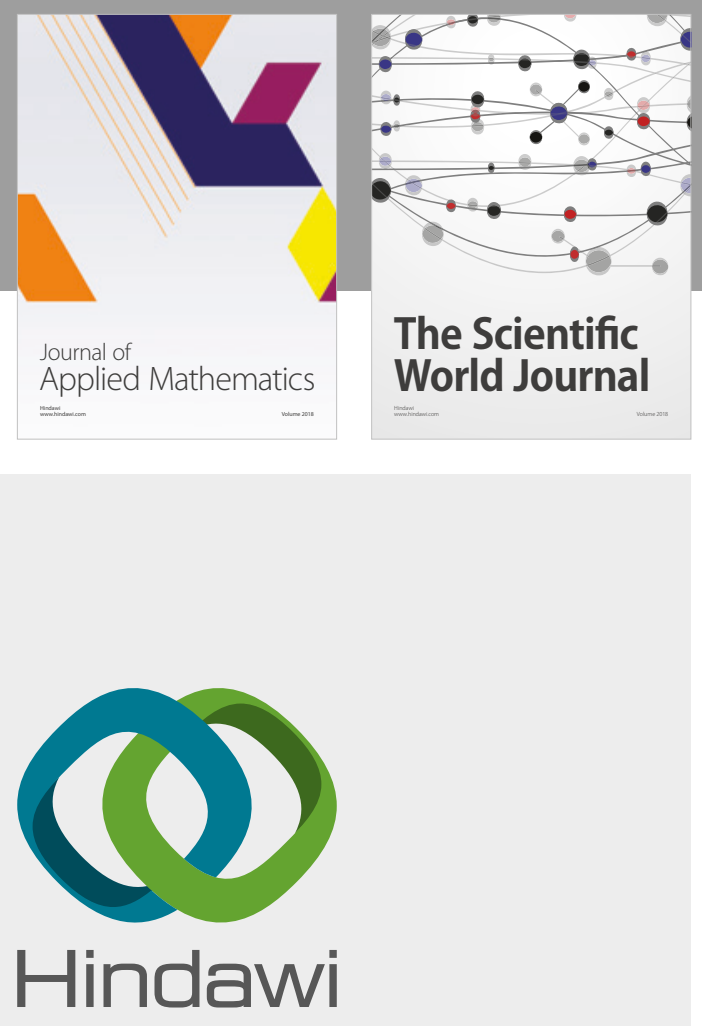

Submit your manuscripts at

www.hindawi.com

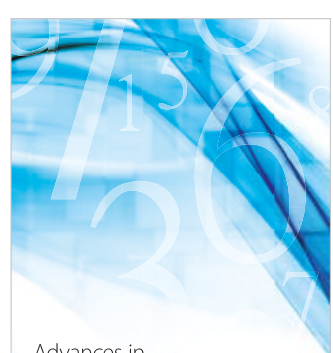

Advances in
Numerical Analysis
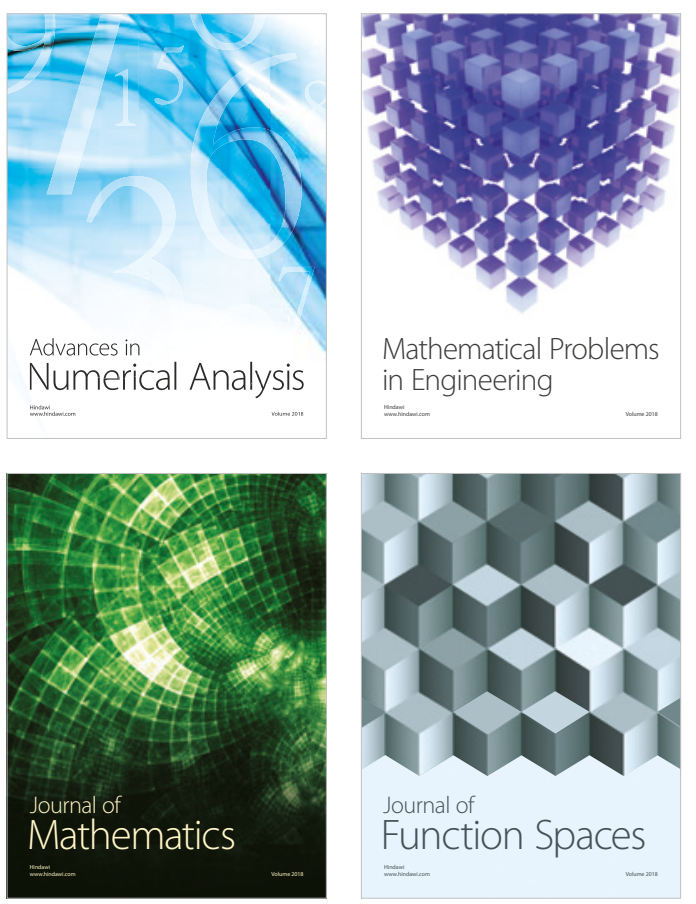

Mathematical Problems in Engineering

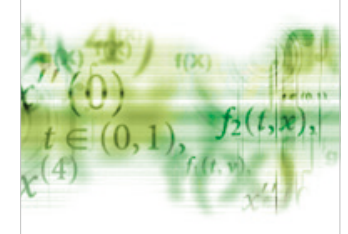

International Journal of

Differential Equations

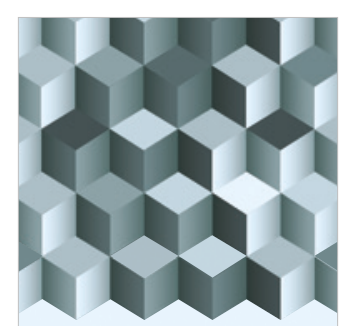

Journal of

Function Spaces

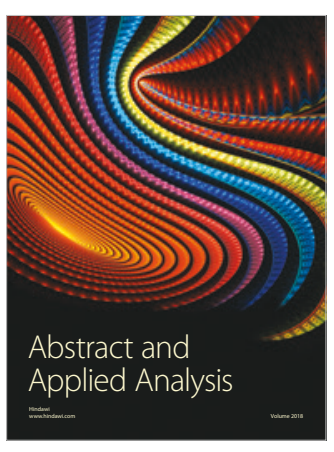

The Scientific

World Journal

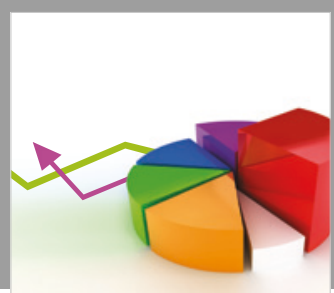

Journal of

Probability and Statistics
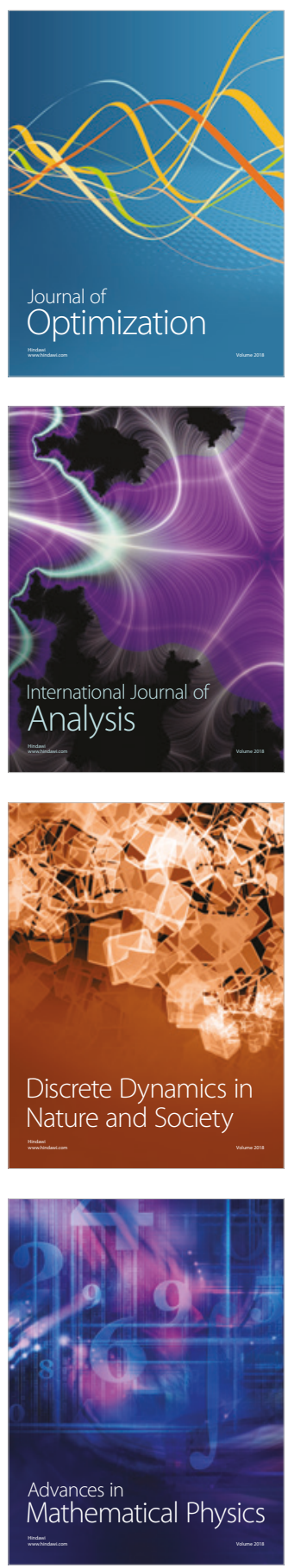